
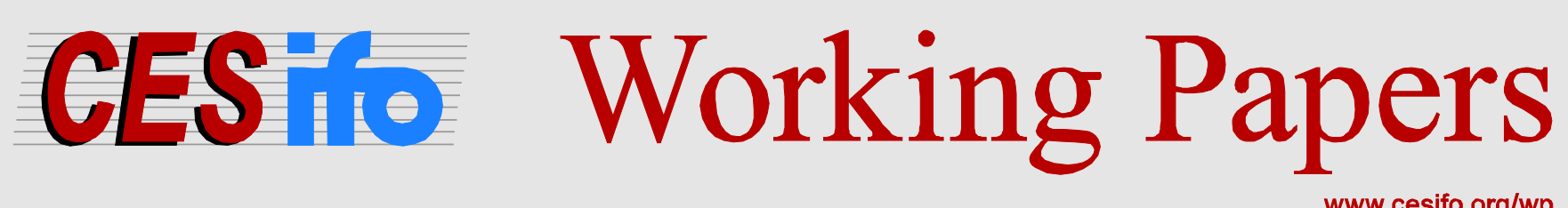

www.cesifo.org/wp

\title{
Dynamic Commercial Lobbying
}

\author{
Thomas Groll \\ Christopher J. Ellis
}

CESIFO WORKING PAPER NO. 4114

CATEGORY 1: Public FinANCE

FEBRUARY 2013

An electronic version of the paper may be downloaded

- from the SSRN website:

- from the RePEc website:

- from the CESifo website:

WWw.SSRN.com

www.RePEc.org

www.CESifo-group.org/wp

\section{CESifo}




\title{
Dynamic Commercial Lobbying
}

\begin{abstract}
This study explains the observed repeated personal interactions between lobbyists and policymakers. The analysis uses a dynamic model of commercial lobbying in which citizens may hire lobbyists to present policy proposals on their behalf to policymakers. It is shown that repeated interactions with lobbyists simplify a policymaker's information problem in the presence of unverifiable information provision and allow a solution to their contracting problem. The welfare implications of these interactions depend on whether the policymakers' information or contracting problem predominates. Further, the policymaker's information problem and financial contributions may actually improve social welfare in comparison to the full information outcome.
\end{abstract}

JEL-Code: D720, D780.

Keywords: dynamic lobbying, influence activities, information acquisition, financial contributions, commercial lobbying, political access, moral hazard.

Thomas Groll

School of International and Public Affairs

Columbia University

New York, NY / USA

tg2451@columbia.edu
Christopher J. Ellis

Department of Economics

University of Oregon

Eugene, OR / USA

cjellis@uoregon.edu

November 2012

First Draft: May 2011

We thank Nicholas Sly and Shankha Chakraborty for comments and suggestions. The work benefited from the comments of participants at the 2010 and 2011 Association for Public Economic Theory meetings and from seminar participants at the University of Birmingham and the University of Oregon. All errors are our own. 


\section{Introduction}

In recent policy debates much attention has been devoted to the activities of lobbyists and how they may exploit, and possibly abuse, personal relationships with policymakers to influence the political process. It is well understood that lobbyists may "purchase" this influence by transferring a variety of valuable resources to policymakers. Common resource transfers include the supply of research reports, legislative drafts, staff, campaign contributions, networking events, gifts, and career opportunities. The social desirability of these transfers is very controversial. It seems clear that some aspects of these transfers, particularly the truthful transmission of information, may improve policymaking, whereas others, perhaps such as campaign contributions, may introduce undesirable distortions. ${ }^{1,2}$ It therefore behooves economists to develop a clear understanding of lobbying. One particular aspect of lobbying that has largely escaped attention is that there are two types of lobbyist engaged in these political influence activities. Until very recently economic inquiry has focused almost exclusively on the lobbying activities of special interest groups, the representatives of which lobby for a subset of policies of direct concern to the group. ${ }^{3}$ However, there exists a second type of lobbyist typically employed by law or public relations

\footnotetext{
${ }^{1}$ The activities of Jack Abramoff the "enfant terrible" of lobbyists in Washington D.C. illustrates some of the controversies. He was known for unorthodox lobbying practices, and pleaded guilty to charges of fraud, tax evasion, and bribery of Congress members (Schmidt and Grimaldi, 2005, 2006). Nevertheless, lobbying is a widespread business practice in almost all government affairs. The New York Times's online service "Topics" even provides a special archive for articles related to lobbying and lobbyists. The implications of lobbying activities and their social benefits depend on the provision of policy relevant information and the potential political capture of the political process: "[...] for the disclosure of efforts by paid lobbyists to influence the decision-making process and actions of the Federal legislative and executive branch officials while protecting the constitutional right of the people to petition the government for a redress of their grievances." (The Lobbying Disclosure Act, 1995 - Purpose and Summary.)

${ }^{2}$ For example, The New York Times reported in 2009 how the same lobbyists, employed by the same law firm and lobbying on behalf of a biotechnology company, provided House members from both parties with statements about the health care reform. Some of these statements were printed in the Congressional Records (Pear, 2009). The extensive Dodd-Frank Wall Street Reform Act and the process of its drafting caused a windfall of lobbying revenues, especially for lobbyists with expertise in financial products and regulation (Becker 2010). LobbyControl, a German non-profit watchdog, reported in 2007 about 100-120 "borrowed public servants" who, as employees of special interest groups or companies, were assigned to work directly in German federal ministries with supervisory and legislative drafting roles. The German government regulated the access to the legislative drafts but the practice is still present (Spiegel Online, 2007; Financial Times Deutschland, 2012).

${ }^{3}$ See Olson's (1965) seminal work on the formation of special interest groups. For a review of special interest group lobbying activities see Persson and Tabellini (2000) as well as Grossman and Helpman (2001); for a detailed review of the rent-seeking literature see Congleton, Hillman and Konrad (2008).
} 
firms who operate on a for-profit basis. ${ }^{4}$ The existence and activities of these commercial lobbyists has received far less attention. This is surprising as commercial lobbyists outnumber "in-house" special interest group lobbyists and are almost entirely responsible for the recent observed growth in U.S. federal lobbying expenditures. Since commercial lobbyists work on behalf of clients for economic profit rather than ideological motives, and since their defining proprietary asset is access to policymakers, it is argued that they face a different economic problem from the biased experts and advocates of special interest groups. Furthermore, since policymakers choose which lobbyists receive scarce political access this allows them to construct incentives that induce the commercial lobbyists to transfer to them their preferred mix of resources.

In what follows we argue that to understand the behavior of commercial lobbyists and their consequences it is necessary to understand the nature of the agency contracts that exist between lobbyists and policymakers. Formal written contracts between lobbyists and policymakers are not observed, and would almost certainly be neither legal nor politically viable. However, there seems to be considerable evidence that informal agency contracts based on the repeated nature of interactions between policymakers and lobbyist are highly prevalent. Evidence for this may be found in recent empirical work by Blanes i Vidal, Draca, and Fons-Rosen (2011) and Eggers (2010) which focus on the importance of personal relationships between lobbyists and politicians by analyzing the "revolving door" phenomenon. The revolving door characterizes the career change by politicians and staff members who become lobbyists and attempt to earn lobbying rents by offering their previous contacts to special interest groups. They find empirical support for the revolving door hypothesis and show that those lobbyists with previous staff experience realize immediate, discontinuous, and permanent losses in lobbying revenues after their previous employer leaves office. Eggers (2010) focuses on lobbyists' and politicians' party affiliation and the revolving door phenomenon. His results show that the revenues of those lobbyists with staff experience are more affected by their party membership and the party in

\footnotetext{
${ }^{4}$ Groll and Ellis (2012) provide a rationale for commercial lobbying activities and analyze the welfare implications of commercial lobbying activities in a static general equilibrium framework. Betrand, Bombardini and Trebbi (2011) show that nowadays only $40 \%$ of lobbyists are "in-house" special interest group lobbyists and that the 1998-2008 growth in U.S. federal lobbying expenditures can be accounted to commercial lobbying activities.
} 
power; whereas former politicians generate lobbying income by offering personal contacts rather than ideological proximity to political incumbents. Other recent empirical work by Bertrand, Bombardini, and Trebbi (2011) tries to disentangle whether lobbyists provide issue expertise to policymakers or offer political access to potential clients. Amongst their results, they show that lobbyists, measured by campaign donations and reported policy issues, follow their political contacts and change their political issues when those politicians change offices or committee assignments and political issues. ${ }^{5}$ They conclude that value of a lobbyist to a client is derived from their political access rather than their expertise.

While the empirical literature seems to point strongly to the importance of ongoing personal relationships in lobbying it does not explain why they matter. This is the issue taken up in this paper. We argue that personal contacts, expressed as repeated relationships with reputation concerns, can explain why contacts matter and how they relate to the observed lobbying practices of providing policy relevant information and financial resources to policymakers. Our study relates to Krozner and Stratmann's (1998) empirical work, in which they argue that the committee system of Congress provides an environment that facilitates repeated interactions and reputation building between special interest groups and politicians. The committee structure and the repeated interactions enable the construction of informal agreements of legislative support in return for campaign contributions in the absence of legal contracts. We formalize and extend these ideas, by including both promised financial contributions and unverifiable information provision, and show that repeated interactions solve an imperfectly informed policymaker's contracting problem for financial contributions and information problem when lobbyists possess private policy relevant information. The arising personal contacts create barriers to entry and positive economic rents for encumbent lobbyists, and also serve as a motivation device to provide costly unobservable efforts.

As Groll and Ellis (2012) pointed out commercial lobbyists differ from the "biased experts" and "advocates" that have been discussed in the economic literature. However they do share specific features with each of these types. Biased experts are characterized

\footnotetext{
${ }^{5}$ Unfortunately, current U.S. federal lobbying regulation and registration provide names and financial amounts for clients and lobbyists but not for policymakers and politicians who are target of their lobbying activities. A lack of transparency that is discussed in Groll (2012).
} 
as agents who possess some form of expertise and private information that is valued by a decision-maker. ${ }^{6}$ In contrast to a commercial lobbyist who competes for political access, which is then sold to clients, an experts' compensation depends on the decision-maker's choice. An advocate is an agent who is expected to provide information to a decisionmaker and argue for the best outcome for a client. For example, Dewatriport and Tirole (1999) show that informational benefits for a decision-maker are maximized when each advocate argues for a specific cause or client. They point out that we observe two types of compensation schemes for advocates: Decision-based rewards and information-based rewards. Decision-based rewards are based on the advocates' achievements for their clients; information-based rewards are based on how advocates achieve outcomes. Their analysis focuses on decision-based rewards and neglects information-based rewards. Commercial lobbyists usually represent many clients and are dependent on political access to policymakers. They have to balance policymakers' demands with clients' objectives in order to be successful. The former is closer to information-based rewards, whereas the latter is closer to decision-based rewards. So it is not immediately clear who the lobbyist's de facto principal is. ${ }^{7}$ We argue that the competition for scarce political access shifts the lobbyists' compensation scheme towards indirect information-based rewards, namely political access, and that policymakers do not need to consult multiple lobbyists if they interact repeatedly.

The current analysis introduces a dynamic commercial lobbying model that builds on both unobservable lobbying efforts and promised, rather than contractible, financial contributions. $^{8}$ Citizens have policy proposals that if enacted yield a private benefit and create either a socially desirable or socially undesirable spillover. To be enacted policy

\footnotetext{
${ }^{6}$ For example, Crawford and Sobel (1982), Gilligan and Krehbiel (1989), Austen-Smith (1994), and Krishna and Morgan (2001) study the behavior of a single or multiple experts with private information who advise an imperfectly informed decision-maker. Krishna and Morgan (2001) provide a review of this literature and show that a biased expert has an incentive to misrepresent information, and a decision-maker may want to consult competing experts to improve the decision-making.

${ }^{7}$ We observe that lobbyists and clients agree to formal contracts. However, "lobbying success fees" are widely illegal and relationships between lobbyists and policymakers in the absence of formal contract seem to persist over time.

${ }^{8}$ The basic model of commercial lobbying, which is presented in Groll and Ellis (2012), focuses on the existence and welfare implications of commercial lobbying activities in a static general equilibrium framework. In the static model, similar to Bennedsen and Feldmann (2002, 2006) as well as Dahm and Porteiro (2008), it is assumed that policymakers can observe both the lobbyists' information acquisition and information signal. This allows policymakers to request their desired levels of verification efforts and financial contributions directly.
} 
proposals must be presented to a policymaker. Citizens can either present their proposals directly to a policymaker or indirectly via a lobbyist. Policymakers value both the spillovers from enacted policy proposals and any financial contributions they receive. Lobbyists may provide policy relevant information and financial contributions to policymakers in exchange for political access. This is sold to clients for economic profit. We show that repeated personal relationships between a policymaker and a lobbyist facilitate a solution to the policymaker's information and contracting problem. The intertemporal interactions enable policymakers to escape a static "cheap talk" game with no information provision and no financial contributions. The motivation for lobbyists to engage in such interactions with costly unobservable efforts arises when policymakers create political barriers to entry and promise lobbyists, as "political insiders", positive future profits. We also show that welfare implications of repeated personal interactions depend on whether the policymakers' information or contracting problem predominates. ${ }^{9}$

\subsection{Other Related Literature}

The current study is related to the lobbying literature that focuses on campaign contributions and information acquisition. ${ }^{10}$ Like Bennedsen and Feldmann (2006) and Dahm and Porteiro (2008) we focus on the interdependency between information acquisition and financial contributions. ${ }^{11}$ Bennedsen and Feldmann (2006) investigate information externalities when multiple interest groups attempt to influence a single policy. The information externality reduces an interest group's incentive to provide information and results in interest groups' specialization in either means. Dahm and Porteiro (2008) show that the provision of information may harm a single interest group and financial contributions complement or substitute for information transfers. We follow most closely the path of Groll and Ellis (2012) who analyze commercial lobbyists who lobby for multiple clients by providing

\footnotetext{
${ }^{9}$ Groll and Ellis (2012) show that financial contributions may decrease a socially inefficient overprovision of information.

${ }^{10}$ For lobbying models that examine financial contributions see for example Whinston and Bernheim (1986), Grossman and Helpman (1994), Besley and Coate (2001). For lobbying models that focus on information provision see for example Crawford and Sobel (1982), Gilligan and Krehbiel (1989), Potters and van Winden (1992), and Austen-Smith (1994). For an overview see Persson and Tabellini (2000) and Grossman and Helpman (2001).

${ }^{11}$ Earlier models, such as Austen-Smith (1995) and Lohmann (1995), modeled campaign contributions as a means to receive access to policymakers for the presentation of information.
} 
financial contributions and policy specific information as private goods. They show that in equilibrium individual lobbyists simultaneously supply both information and financial contributions to policymakers. The current analysis relaxes the assumptions of observable information and the ex ante provision financial contributions of these models. It focuses on the implications of how in equilibrium the repeated interactions between policymakers and commercial lobbyists solve the policymakers' information and contracting problems.

The current study is also related to the extensive literature that focuses on incomplete information, repeated interactions, and barriers to entry. ${ }^{12}$ For example in Diamond's (1991) model a borrower's current repayments improve their credit rating and allow them to borrow at lower interest rates in the future. Here, commercial lobbyists undertake current verification efforts, which are positively correlated with quality signals that policymakers receive, to establish a reputation that is rewarded with political access in the future. The interactions between commercial lobbyists and policymakers who grant political access in exchange for unobservable efforts is also related to the principal-agent literature. However, as Holmstrom (1981) points out, principal-agent models with asymmetric information may require complex sharing rules that may entail serious limitations with respect to legal enforcement. Simple fixed-wage contracts may perform better whenever the complex contracts cannot be enforced. ${ }^{13}$ Simpler contracts with prohibitively costly bonding have been addressed in the economic literature of efficiency wages with shirking. This literature addresses the relationship between a worker's productivity and compensation. For example, Shapiro and Stiglitz (1984) show that employers have an incentive to offer higher wages that increase a worker's opportunity cost of shirking and being fired. The resulting higher equilibrium wages imply a higher level of unemployment that serves as a discipline device. ${ }^{14}$ In Esfahani and Salehi-Isfahani (1989) as well as Black and Garen

\footnotetext{
${ }^{12}$ The notion that current actions can generate future information is introduced by Kreps and Wilson (1982), as well as Milgrom and Roberts (1982). Both address Selten's (1978) Chain Store Paradox and analyze incumbents' and entrants' actions in a repeated game with asymmetric information. Market incumbents undertake current investments to create a reputation that deters future entry.

${ }^{13}$ For an extensive survey of the economic literature of moral hazard and dynamic moral hazard problems see Bolton and Dewatriport (2005).

${ }^{14}$ The authors assume that the likelihood of detecting shirking is exogenous and that a worker's effort choice is dichotomous. Sparks (1986) allows for continuous effort and employer's can observe with some positive probability an employee's effort level. As a result, an employer announces a minimum effort level and dismisses shirking workers. In equilibrium, workers undertake the required minimum effort and receive
} 
(1991), an employer receives a signal about a worker's performance that is positively correlated with the worker's effort. The worker's choice of effort is continuous, and the employer announces a performance standard for a continued work relationship. ${ }^{15}$ In both models, some unlucky non-shirking workers are in equilibrium dismissed, creating vacancies for entry. In our model, some unlucky lobbyists lose political access and there is some entry but the repeated interactions create barriers to entry and create positive economic rents for lobbyists. Our analysis also provides some additional insights. First, a policymaker, as the principal, does not bear any explicit cost when rewarding a lobbyist's performance. A policymaker allocates scarce time that is valued by lobbyists as well as citizens. The political access, as indirect compensation for a lobbyist, can be sold to potential clients in the market for lobbying services which creates incentives to undertake a costly effort. Second, both a lobbyist's verification effort and financial contribution is continuous but the degree of monitoring differs. Verification effort can only be imperfectly monitored whereas financial contributions can be perfectly monitored after they have been made. The former reflects the policymaker's information problem in the presence of asymmetric information and the latter the policymaker's contracting problem in the absence of legally binding contracts.

\subsection{Outline}

The structure of this study is as follows: Section 2 presents the dynamic model and characterizes a political access rule. Section 3 characterizes the steady state with a simultaneous equilibrium in the lobbying labor market, the market for commercial lobbying services, and the market for political access. Section 4 analyses the social desirability of the equilibrium. Section 5 concludes and discusses the findings.

${ }^{15}$ Esfhani and Salehi-Isfahani (1989) focus on the observed dualism, the coexistence of formal and informal sectors, and the wage gaps and unemployment rates across both sectors. They argue that workers' effort is less observable in the formal sector because of complexity. Black and Garen (1991) focus on industry wage differentials and argue that observed wage gaps result from differences in labor performance standards or observability of workers' efforts.
} 


\section{The Dynamic Model}

The dynamic version of the commercial lobbying model is in discrete time and consists of a society with citizens, $c$, lobbyists, $l$, and policymakers, $p$. All agents are risk-neutral and infinitely lived. Each citizen has a single policy proposal in any period $t$ that if enacted will yield a private benefit of $\pi^{c}>0$ and create a social spillover of $e_{t}^{c}$ with $e_{t}^{c} \in\{s,-s\}$ and $s>0$. A policy proposal with a positive spillover would be socially desirable whereas one with a negative spillover is assumed to be socially undesirable - i.e., $\pi^{c}-s<0$. The spillover and hence social value of any policy proposal is unknown to society in $t$, but is observed a period later in $t+1$. Ex ante each society member knows the exogenous probability of a positive spillover, $\rho\left(e^{+}\right)$, and the complimentary probability for a negative one, $\rho\left(e^{-}\right)=1-\rho\left(e^{+}\right)$. Overall, the expected social value of any policy proposal is positive, and each individual receives an identical share of all realized spillovers.

A policy proposal can be presented to a policymaker either directly by the citizen or indirectly by a lobbyist, who operates for profit. Lobbyists have two capabilities: They have a verification technology that allows them to investigate the welfare effects of policy proposals, and they can make financial contributions to policymakers. Each policymaker has a time constraint for enacting policy proposals but no independent verification technology. Every policymaker announces political access rules to citizens and lobbyists, $\tilde{a}^{c p}($. and $\tilde{a}^{l p}($.$) , that allocate time between citizens and lobbyists for the presentation of policy$ proposals. The maximum number of enacted policy proposals is equal to the policymakers total time in a period $A_{t} \cdot{ }^{16}$ All policy proposals presented that are not known by a policymaker to have received a negative verification signal are enacted.

The timing of the model for each time period $t$ is the following: First, all policymakers simultaneously announce individual access rules to citizens and lobbyists. Second, citizens choose to become a lobbyist or continue as a citizen with a policy proposal. Third, lobbyists accept a certain number of proposals from clients and may investigate some of them. Finally, lobbyists promise financial contributions and present a portfolio of policy proposals to policymakers, which are immediately enacted.

\footnotetext{
${ }^{16}$ We shall show shortly that in equilibrium a policymaker would never choose to leave any time unallocated.
} 
The actions by lobbyists and the interactions between lobbyists and policymakers are

unobservable to citizens. However, citizens can observe the amount of political access, $\tilde{a}_{t}^{l p}$, and the number of clients, $n_{t}^{l}$, of each lobbyist. Policymakers know the characteristics of the lobbyists' verification technology but cannot observe the lobbyists' verification efforts, received verification signals, and financial contributions in $t$. However, each policymaker observes in $t+1$ the financial contributions made by a lobbyist to him and the previous period's realized spillovers of enacted proposals. All individuals know the distribution of society's members in the population, $T$, in $t$-i.e., $T=P_{t}+C_{t}+L_{t}-$ and the appointment of policymakers follows from some commonly known constitutional rule with $P_{t}=\bar{P}$.

There are three markets in the economy; a labor market on which individuals choose either to be citizens of lobbyists, a market for professional lobbying services on which citizens and lobbyists trade intermediation services, and a market for political access on which lobbyists and policymakers transact over the policymakers scarce time. The labor market is assumed to be perfectly arbitraged, that is the expected value to an individual of choosing to be a lobbyist or citizen is equal. The market for intermediation services is assumed to be perfectly competitive with a market clearing service fee of $k_{t}$. The market for political access is cleared via equilibrium implicit, non-contractable, agency contracts between policymakers and lobbyists. These agency contracts take the form of access rules that reward finacial contributions and information quality with future political access. Further details about the dynamic model are presented in the following.

\subsection{Citizens}

There are $C_{t}$ citizens and each has a policy proposal. If a policy proposal is enacted in period $t$, then the citizen realizes the private benefit of $\pi^{c}$, and additionally receives a share of aggregate spillovers from all enacted policy proposals, $A_{t}$. If a policy proposal is not enacted it expires at the end of the period and is replaced by a new one. Citizens may costlessly present their proposals directly to a policymaker or hire a commercial lobbyist to present the proposal on their behalf for a fee of $k_{t}$. A citizen can hire only one lobbyist in $t$. 
The payoff for citizen $c$ in $t$ is then:

$$
\Pi_{t}^{c}= \begin{cases}\pi^{c}+\frac{1}{T} \sum_{c=1}^{A_{t}} e_{t}^{c} & \text { if } c \text { gains access directly in } t \\ \frac{1}{T} \sum_{c=1}^{A_{t}} e_{t}^{c} & \text { if } c \text { gains no access in } t \\ \pi^{c}-k_{t}+\frac{1}{T} \sum_{c=1}^{A_{t}} e_{t}^{c} & \text { if lobbyist } l \text { presents } c^{\prime} \text { 's proposal in } t, \text { or } \\ -k_{t}+\frac{1}{T} \sum_{c=1}^{A_{t}} e_{t}^{c} & \text { if lobbyist } l \text { does not present } c^{\prime} \text { 's proposal in } t .\end{cases}
$$

If all policymakers exhaust their time constraints, then aggregate spillovers are invariant with respect to individual citizens choices, hence citizens are motivated entirely by the private benefits from their proposals enactment.

\subsubsection{Citizens' Lobbying Labor Supply}

Each citizen takes policymakers' political access rules by as given. They then choose whether to remain a citizen or become a lobbyist. Should they choose the latter they are assumed to have free access to the verification technology. The citizen's entry decision depends on the payoffs for citizens, $\Pi_{t}^{c}$, and lobbyists, $\Pi_{t}^{l}$, in $t$, as well as the expected lifetime payoffs for citizens and lobbyists. More important for the entry decision for citizens is whether or not there is political access available to entrants, which they could then offer to potential clients - i.e., $\sum_{p=1}^{\bar{P}} \tilde{a}_{t}^{l p} \geq 0$, where $\tilde{a}_{t}^{l p}$ is lobbyist $l$ 's political access.

\subsubsection{Citizens' Demand for Commercial Lobbying Services}

A citizen can try to approach a policymaker directly at no cost. If direct access is granted, then their proposal is presented and enacted. However, political access is uncertain and citizens have to form expectations of the likelihood of success. The citizens' expected payoff from direct political access is given by

$$
\frac{\sum_{p=1}^{\bar{P}} \tilde{a}_{t}^{c p}}{C_{t}-N_{t}} \pi^{c} \geq 0 \text { for all } t
$$

where $\tilde{a}_{t}^{c p} \in\{0,1\}, N_{t}$ is the number of all lobbying industry clients, so $C_{t}-N_{t}$ is the number of citizens competing for direct political access. The citizens alternative is to hire 
a lobbyist to present the policy proposal. A potential client cannot observe lobbyists' actions behind closed doors and therefore has to form expectations of the likelihood that their proposal will be presented to a policymaker. A citizen uses the lobbyist's political access, $\tilde{a}_{t}^{l p}$, and the number of clients, $n_{t}^{l}$, to form an expectation that their proposal will be presented by $l$. The expected payoff from hiring a lobbyist depends on the likelihood of a successful mandate, the private benefit of the policy proposal, and the lobbying service fee. Finally, a citizen has the alternative of being politically inactive, which yields a certain private benefit of zero.

If citizens expect no direct political access to policymakers - i.e., $\sum_{p=1}^{\bar{P}} \tilde{a}_{t}^{c p}=0$ - then the alternatives are reduced to hiring a lobbyist or being politically inactive. As a result, the individual demand for commercial lobbying can be reduced to

$$
\frac{\tilde{a}_{t}^{l p}}{n_{t}^{l}} \pi^{c}-k_{t} \geq 0 \text { for all } l \text { and } t
$$

\section{$2.2 \quad$ Lobbying Firms}

There are $L_{t}$ lobbyists each of whom constitutes a lobbying firm. A lobbyist accepts proposals from $n_{t}^{l}$ clients who each pay a lobbying service fee of $k_{t}$ per proposal. Lobbyists possess a verification technology that allows them to investigate the potential spillovers of policy proposals. This technology returns a private signal $x, x \in\left\{x^{+}, x^{-}\right\}$, which improves the lobbyist's information about a proposal's expected spillover. If the signal is positive, $x^{+}$, then the exogenous probability for a positive spillover is higher than without investigation, $\rho\left(e^{+} \mid x^{+}\right)>\rho\left(e^{+}\right)$; a negative signal, $x^{-}$, increases the likelihood for a negative spillover, $\rho\left(e^{-} \mid x^{-}\right)>\rho\left(e^{-}\right)$. Investigated proposals with a positive signal have a greater expected social value than unverified proposals; verified proposals with a negative signal have a negative expected social value. This is summarized as follows:

$$
\begin{gathered}
\rho\left(e^{+} \mid x^{+}\right)\left(\pi^{c}+s\right)+\rho\left(e^{-} \mid x^{+}\right)\left(\pi^{c}-s\right)>\rho\left(e^{+}\right)\left(\pi^{c}+s\right)+\rho\left(e^{-}\right)\left(\pi^{c}-s\right) \\
>0>\rho\left(e^{+} \mid x^{-}\right)\left(\pi^{c}+s\right)+\rho\left(e^{-} \mid x^{-}\right)\left(\pi^{c}-s\right) .
\end{gathered}
$$

The verification of proposals causes costs that are captured by the increasing convex 
cost function $F\left(m_{t}^{l p}\right)$, where $m_{t}^{l p}$ is the number of proposals that are investigated for the lobbyist's only political contact, $p_{t}^{l p}$. We also assume that all proposals whether verified of not incur the lobbyist a basic processing cost captured by the function $G\left(n_{t}^{l}\right)$ which is also increasing and convex. ${ }^{17}$ Depending on the political access rule, $\tilde{a}^{l p}($.$) , a lobbyist may$ present verified proposals as well as some unverified proposals, $u_{t}^{l p}$, to the policymaker. Any remaining unpresented proposals, $r_{t}^{l}$, disappear in the firm, so that $n_{t}^{l}=m_{t}^{l p}+u_{t}^{l p}+r_{t}^{l}$. Finally, depending on the policymaker's political access rule a lobbyist may also make a financial contribution to the policymaker, $f_{t}^{l p}$. Both the verification effort and the financial contribution are private information in $t .^{18}$

The payoff for lobbyist $l$ in $t$ is

$$
\Pi_{t}^{l}=k_{t} n_{t}^{l}-G\left(n_{t}^{l}\right)-F\left(m_{t}^{l p}\right)-f_{t}^{l p}+\frac{1}{T} \sum_{c=1}^{A_{t}} e_{t}^{c}
$$

\subsection{Policymakers}

Each of the $\bar{P}$ policymakers can approve a maximum of $A^{p}$ proposals in $t$, and all policymakers together enact $A_{t}$ proposals with $A_{t}=\bar{P} A_{t}^{p} \leq \bar{P} A^{p}$. In each period, a policymaker receives an ego rent for holding office, $\theta$, may receive financial contributions, $f_{t}^{l p}$, from $l_{t}^{p}$ lobbying contacts, and enjoys a share of spillovers from all enacted policy proposals. ${ }^{19} \mathrm{~A}$ policymaker may discount financial contributions by $\alpha$ with $\alpha \in[0,1]$. This can be interpreted as the policymaker's degree of dishonesty or the effectiveness of in-kind transfers.

Policymakers do not have an independent verification technology, and enact all presented proposals. However, each policymaker $p$ can announce access rules to citizens and lobbyists, $\tilde{a}^{c p}($.$) and \tilde{a}^{l p}($.$) , that allocate the policymaker's time according to the specified$ implicit conditions. These access rules may be influenced by lobbyists' verification efforts and financial contributions. Naturally, the allocation of access is restricted by the policymaker's time constraint - i.e., $A_{t}^{p} \geq \sum_{c=1}^{c_{t}^{p}} \tilde{a}_{t}^{c p}+\sum_{l=1}^{l_{t}^{p}} \tilde{a}_{t}^{l p}$. Note that the policymaker faces no

\footnotetext{
${ }^{17}$ It is also assumed that $F^{\prime}(0)=G^{\prime}(0)=0$ and $F^{\prime \prime \prime}() \geq$.0 .

${ }^{18} f_{t}^{l p}$ may be thought of as a promise that remains to be honored

${ }^{19}$ The only purpose of the ego rent is to provide some form of benefit to the policymaker that is independent of his actions and provides some compensation for foregoing private benefits he may would enjoy as if he were a citizen. Whether $\theta>0$ or $\theta=0$ has no effect on the qualitative results of this analysis.
} 
explicit cost for enacting policy proposals and does not compensate citizens or lobbyists for the presentation of policy proposals.

The payoff for policymaker $p$ in $t$ is

$$
\Pi_{t}^{p}=\theta+\alpha \sum_{l=1}^{l_{t}^{p}} f_{t}^{l p}+\frac{1}{T} \sum_{c=1}^{A_{t}} e_{t}^{c}
$$

where the aggregate spillovers depends on presented policy proposals. The expected quality of spillovers from enacted policy proposals, $E\left[\sum_{c=1}^{A_{t}} e_{t}^{c}\right]$, depends on the number of unverified proposals presented by citizens or lobbyists and verified policy proposals with their received verification signals presented by lobbyists.

\subsection{Political Access Rules}

Each policymaker faces a trade-off between allocating political access to citizens or lobbyists: Citizens provide policy proposals but lobbyists provide multiple policy proposals, verification effort, and financial contributions. A political access rule for a citizen, $\tilde{a}^{c p}($.$) ,$ may only specify whether a citizen can or cannot present a policy proposal. However, a policymaker's access rule for a lobbyist, $\tilde{a}^{l p}($.$) , can specify the desired quality of presented$ policy proposals, the size of financial contributions, and the number of policy proposals required.

It is assumed that policymakers and lobbyists cannot write legally binding contracts that specify the quality of presented portfolios and the magnitude of financial contributions. ${ }^{20}$ However, it is reasonable to assume that there are some "insider rules" or lose agreements that serve as implicit contracts amongst "political insiders." These insider rules give the conditions under which policymakers grant political access to lobbyists, and serve to incent the lobbyists to engage in costly information verification activities and to make financial contributions. A relatively simple and legally unobjectionable incentive device for a policymaker is the implicit threat of terminating a personal relationship. ${ }^{21}$ With the end

\footnotetext{
${ }^{20}$ This follows from the observation that such contracts are usually not legally enforceable or that the enforcement and disclosure of such contracts may have adverse effects for policymakers and lobbyists. Adverse effects could be a loss of credibility or just public envy.

${ }^{21}$ This is captured by Holmstrom's (1981) analysis that simple fixed-wage contracts may not be generally optimal but might perform better in circumstances when the optimal contract itself would be complex and
} 
of a personal relationship, and the implied loss of political access, a lobbyist can no longer offer this access to clients. So a lobbyist would have to approach another policymaker to replace the lost access or go out of business.

The political access rules we study and the associated issue of monitoring lobbyists' efforts is similar to the problem of monitoring workers' efforts and rewarding them with fixed wages as studied in Esfahani and Salehi-Isfahani (1989) and Black and Garen (1991). The two key differences are that; lobbyists' efforts are indirectly compensated with political access that is valued in the market for lobbying services, and that lobbyists' undertake efforts with different monitoring characteristics. Verification efforts are unobservable at $t$ and imperfectly observable at $t+1$, financial contributions are unobservable at $t$ and perfectly observable at $t+1$.

\subsubsection{Unobservable Effort, Monitoring, and Termination}

A lobbyists' current verification effort and financial contributions are private information in $t$, and this creates an incentive for a lobbyist to promise effort but not deliver. ${ }^{22}$ A lobbyist only undertakes costly effort if it is positively related to potential rewards. A policymaker can identify perfectly in $t+1$ a lobbyist's financial contribution that was made in $t$. So if a policymaker received at least the announced minimum financial contribution of $\bar{f}_{t}^{l p}$, then the policymaker does not terminate the relationship and rewards the lobbyist with political access in $t+1$. Therefore, the likelihood for a lobbyist of being dropped given the announced $\bar{f}_{t}^{l p}$ is therefore either 0 or 1 and depends entirely on the lobbyist's choice of $f_{t}^{l p}$. However, a policymaker observes a lobbyist's verification effort neither in $t$ nor in $t+1$. The policymaker does however observe the quality of spillovers from policy proposals enacted in $t, q_{t}^{l p}$, and can thus form an expectation about the lobbyist's verification efforts. ${ }^{23}$ The observed quality can be used by the policymaker as a performance measure that is positively related to the lobbyist's verification effort. Future political access may then be too expensive to enforce.

${ }^{22}$ It is never optimal for a lobbyist with political access to become a citizen in $t$ if $k_{t} n_{t}^{l}-G\left(n_{t}^{l}\right) \geq \Pi_{t}^{c} \geq 0$. If this condition would not hold in equilibrium, then nobody would want to be a lobbyist and there would be no commercial lobbying in any market equilibrium.

${ }^{23} \mathrm{~A}$ policymaker knows in $t+1$ the number of presented proposals, $\tilde{a}_{t}^{l p}$, and the number of enacted policy proposals with positive and negative spillovers. This allows the policymaker to observe the quality of presented policy proposals, $q_{t}^{l p}$. 
conditioned on observed quality creating a relationship between efforts and rewards.

To provide a measure of the expected quality of a portfolio of policy proposals presented by lobbyist $l$ to policymaker $p$ we adopt the share of total proposals that are expected to realize positive spillovers, which may be written as 24

$$
\begin{aligned}
E_{t}\left[q_{t}^{l p}\right] & =\frac{\rho\left(x^{+}\right) \rho\left(e^{+} \mid x^{+}\right) m_{t}^{l p}+\rho\left(e^{+}\right) u_{t}^{l p}}{\tilde{a}_{t}^{l p}} \\
& =\rho\left(e^{+}\right)+\frac{\rho\left(x^{+}\right)\left[\rho\left(e^{+} \mid x^{+}\right)-\rho\left(e^{+}\right)\right] m_{t}^{l p}}{\tilde{a}_{t}^{l p}}
\end{aligned}
$$

where $\tilde{a}_{t}^{l p}=\rho\left(x^{+}\right) m_{t}^{l p}+u_{t}^{l p}$ and $\tilde{a}_{t}^{l p}$ is treated by the lobbyist as a parameter, however $m_{t}^{l p}$ and $u_{t}^{l p}$ are both choices. ${ }^{25}$ The expected quality of presented proposals depends on the lobbyist's political access and the expected information improvement through the verification of proposals.

In period $t+1$ a policymaker, having observed the quality of the portfolio presented to them by a lobbyist in $t$, may form a conditional expectation of the verification effort the lobbyist expended $t$, that is

$$
E_{t+1}\left[m_{t}^{l p}\right]=\frac{q_{t}^{l p}-\rho\left(e^{+}\right)}{\rho\left(x^{+}\right)\left[\rho\left(e^{+} \mid x^{+}\right)-\rho\left(e^{+}\right)\right]} \tilde{a}_{t}^{l p},
$$

where $\tilde{a}_{t}^{l p}$ and $q_{t}^{l p}$ and are known to the policymaker in $t+1$.

Each policymaker can announce a quality threshold for policy proposals' spillovers, $\bar{q}_{t}^{l p}$, that serves as a minimum performance standard and determines whether or not a policymaker terminates a relationship with a lobbyist in $t+1$. If a policymaker observes $q_{t}^{l p} \geq \bar{q}_{t}^{l p}$ in $t+1$, then the relationship continues and the lobbyist receives political access in $t+1$; if a policymaker observes $q_{t}^{l p}<\bar{q}_{t}^{l p}$, then the relationship is terminated and the policymaker allocates the lobbyist's political access to another agent.

In Esfahani and Salehi-Isfahani (1989), the principal observes a signal that is equal to the agent's effort plus an unobservable error term, which is characterized with a continuous

\footnotetext{
${ }^{24}$ It might seem that this should also include a term $\rho\left(x^{-}\right) \rho\left(e^{+} \mid x^{-}\right) m_{t}^{l p}$, but these proposals would not be presented by the lobbyist who would prefer to replace them in the portfolio with an unverified proposal.

${ }^{25}$ The notion that a lobbyist would not present policy proposals with negative verification signals is made precise shorty.
} 
bell-shaped density function. Since a bell-shaped density function does not guarantee a unique solution to the agent's optimization problem and a continuous best-response function in a principal-agent framework, they make additional assumptions about the agent's cost of efforts to ensure a solution. ${ }^{26}$

The current problem has a different information structure from the one studied by Esfahani and Salehi-Isfahani (1989). Each policy proposal has either a positive or negative spillover. Further, the lobbyist's verification technology returns either a positive or a negative signal. Given the binary outcomes and exogenous probabilities, the probability of achieving an announced quality threshold follows a hypergeometric probability distribution. The hypergeometric probability distribution is discrete but can be, for specific parameter values, approximated to either a Poisson or a normal probability distribution. ${ }^{27}$ Following Jewitt (1988), the Poisson probability distribution fulfills the desired characteristics for the first-order approach of solving principal-agent problems. Unfortunately, the approximation of the hypergeometric probability distribution to a Poisson probability distribution requires that the number of presented proposals with a positive verification signal is relatively small in comparison to the lobbyist's portfolio. So the statistically appropriate approximation would be the normal distribution.

Using (2.7), the observed quality of enacted policy proposals can be approximated by

$$
q_{t}^{l p}=\frac{\rho\left(x^{+}\right)\left[\rho\left(e^{+} \mid x^{+}\right)-\rho\left(e^{+}\right)\right] m_{t}^{l p}}{\tilde{a}_{t}^{l p}}+\epsilon_{t}^{l p},
$$

where $\epsilon_{t}^{l p}$ has a mean of $\rho\left(e^{+}\right)$and is normally distributed. The likelihood for a lobbyist of being terminated can be written as

$$
\begin{aligned}
\operatorname{Pr}\left(q_{t}^{l p} \leq \bar{q}_{t}^{l p}\right) & =\operatorname{Pr}\left(\epsilon_{t}^{l p} \leq \bar{q}_{t}^{l p}-\frac{\rho\left(x^{+}\right)\left[\rho\left(e^{+} \mid x^{+}\right)-\rho\left(e^{+}\right)\right] m_{t}^{l p}}{\tilde{a}_{t}^{l p}}\right) \\
& =\delta\left(\bar{q}_{t}^{l p}, m_{t}^{l p}\right)
\end{aligned}
$$

\footnotetext{
${ }^{26}$ Similarly, in Black and Garen (1991), the principal observes a similar performance signal but the error term is normally distributed.

${ }^{27}$ See Fahrmeir et al. (1997).
} 
with $\frac{\partial \delta\left(\bar{q}_{t}^{l p}, m_{t}^{l p}\right)}{\partial \bar{q}_{t}^{l p}}>0$ and $\frac{\partial \delta\left(\bar{q}_{t}^{l p}, m_{t}^{l p}\right)}{\partial m_{t}^{l p}}<0 .{ }^{28}$ A lobbyist's verification effort reduces the likelihood of termination and may provide an incentive to undertake unobservable effort to maintain the relationship. ${ }^{29}$

\subsubsection{The Political Access Rule for Lobbyists}

To summarize, the political access rule for a lobbyist, $\tilde{a}^{l p}($.$) , specifies the policymaker's$ performance expectation, the minimum financial contribution, and the promised future political access - i.e., the access rule is a triple of $\left\{\bar{q}_{t}^{l p}, \bar{f}_{t}^{l p}, \tilde{a}_{t}^{l p}\right\}$. The lobbyist takes this access rule as given and forms a best-response of $m_{t}^{*}=m($.$) and f_{t}^{*}=f($.$) that maximizes$ the lobbyist's expected lifetime payoff. Further, each lobbyist takes $k_{t}$ as given and chooses the number of clients, $n_{t}^{*}=n($.$) . The policymaker takes m_{t}^{*}, f_{t}^{*}, n_{t}^{*}$, and $k_{t}$ as given and chooses $\bar{q}_{t}^{*}$ as well as $\bar{f}_{t}^{*}$ to maximize their own expected lifetime payoff. If a relationship with a lobbyist is terminated by a policymaker, then the lobbyist's political access is allocated to an entering lobbyist who is becoming part of the political establishment.

\subsection{The Lobbyist's Optimization Problem}

Each lobbyist takes the lobbying service fee, $k_{t}$, the citizen's current payoff, $\Pi_{t}^{c}$, and the political access rules of policymakers, $\tilde{a}^{l p}($.$) , with \tilde{a}_{t}^{l p}, \bar{q}_{t}^{l p}$, and $\bar{f}_{t}^{l p}$ as given. In each period, a lobbyist chooses their number of clients, $n_{t}^{l}$, the number of proposals to verify, $m_{t}^{l p}$, and the financial contribution to make, $f_{t}^{l p}$, taking into account the impact of these choices on the likelihood of maintaining their relationship with a policymaker. ${ }^{30}$ A lobbyist anticipates that the presentation of a proposal with a negative verification signal has a negative effect on the expected quality of the presented portfolio. Hence, the lobbyist's optimal portfolio of policy proposals includes only proposals with positive verification signals and unverified proposals - i.e., $\tilde{a}_{t}^{l p}=\rho\left(x^{+}\right) m_{t}^{l p}+u_{t}^{l p} .{ }^{31}$ The expected lifetime payoff at the beginning of

\footnotetext{
${ }^{28}$ In the following, $\delta\left(\bar{q}_{t}^{l p}, m_{t}^{l p}\right)$ is written as $\delta\left(\bar{q}^{l p}\right)$ for notational reasons.

${ }^{29}$ It is possible for the policymaker to increase the number of observations by to incorporating a lobbyist's performance history. The analysis abstracts from the optimal political access rules and focuses on how repeated personal interactions can solve a policymaker's information and contracting problem.

${ }^{30}$ The number of presented but unverified proposals, $u_{t}^{l p}$, follows from $(2.12)$ and the choice of $m_{t}^{l p}$; the number of disappearing policy proposals, $r_{t}^{l}$, follows from $(2.13),(2.12)$, and $m_{t}^{l p}$.

${ }^{31}$ The number of presented proposals is equal to the granted political access. The presentation of policy proposals itself does not cause any costs for lobbyists. So lobbyists with a sufficient number of clients have
} 
$t+1$ of a lobbyist is $V^{l}$ and of a citizen $V^{c}$. Both are parametrically given in the lobbyist's optimization problem. The lobbyists' discount rate is $r$ with $r \in[0,1]$. The lobbyist's optimization problem in $t$ is

$$
\max _{n_{t}^{l}, m_{t}^{l,}, f_{t}^{l p}} E\left[\Pi^{l}\right]=k_{t} n_{t}^{l}-G\left(n_{t}^{l}\right)-F\left(m_{t}^{l p}\right)-f_{t}^{l p}+\frac{\delta\left(\bar{q}^{l p}\right)}{1+r} V^{c}+\frac{\left(1-\delta\left(\bar{q}^{l p}\right)\right)}{1+r} V^{l}
$$

s.t. a current political access constraint of

$$
\tilde{a}_{t}^{l p}=\rho\left(x^{+}\right) m_{t}^{l p}+u_{t}^{l p} \text { for all } t
$$

with Lagrange multiplier $\lambda_{t}^{l p}$, and the lobbyist's portfolio of clients' proposals

$$
n_{t}^{l}=m_{t}^{l p}+u_{t}^{l p}+r_{t}^{l} \text { for all } t
$$

with Lagrange multiplier $\mu_{t}^{l p}$. It is not optimal for a lobbyist with political access to become a citizen in $t$ if $k_{t} n_{t}^{l}-G\left(n_{t}^{l}\right) \geq \Pi_{t}^{c}$. Were this true, then the solution is trivial because no society member would want to be a lobbyist and there would be no equilibrium with commercial lobbying.

A lobbyist chooses; the number of verified proposals, $m_{t}^{l p}$, and, simultaneously, makes a financial contribution, $f_{t}^{l p}$, with the knowledge that the if the financial contribution falls short of that required then the probability of dismissal is unity. ${ }^{32}$ The first-order condition for the optimal number of clients can be written as

$$
\frac{\partial E\left[\Pi^{l}\right]}{\partial n_{t}^{l}}=k_{t}-\frac{\partial G\left(n_{t}^{l}\right)}{\partial n_{t}^{l}} \leq 0
$$

and for verification effort

$$
\frac{\partial E\left[\Pi^{l}\right]}{\partial m_{t}^{l p}}=-\frac{\partial F\left(m_{t}^{l p}\right)}{\partial m_{t}^{l p}}-\frac{\partial \delta\left(\bar{q}^{l p}\right)}{\partial m_{t}^{l p}} \frac{\left(V^{l}-V^{c}\right)}{1+r}-\rho\left(x^{+}\right) \lambda_{t}^{l p}-\mu_{t}^{l p} \leq 0 .
$$

no incentive to dispose political access.

${ }^{32}$ One may argue that the choice of verification is sequential. That is, a lobbyist observes the verification signal for a proposal and decides whether another proposal should be or should not be verified in order to balance the lobbyist's chances costs. However, one can imagine that a sequential process is much more time-consuming and costly. So in reality, one may observe a mixture of both. 
Note that $(2.15)$ depends on whether $n_{t}^{l} \geq m_{t}^{l p}$. If $u_{t}^{l p}>0$, then $\lambda_{t}^{l p}=0$ and $\mu_{t}^{l p}=0$. Otherwise there would be a corner solution with $\tilde{a}_{t}^{l p}=\rho\left(x^{+}\right) m_{t}^{l p}$.

The second-order conditions are

$$
\frac{\partial^{2} E\left[\Pi^{l}\right]}{\partial n_{t}^{l^{2}}}=-\frac{\partial^{2} G\left(n_{t}^{l}\right)}{\partial n_{t}^{l^{2}}}<0
$$

and

$$
\frac{\partial^{2} E\left[\Pi^{l}\right]}{\partial m_{t}^{l p^{2}}}=-\frac{\partial^{2} F\left(m_{t}^{l p}\right)}{\partial m_{t}^{l p^{2}}}-\frac{\partial^{2} \delta\left(\bar{q}^{l p}\right)}{\partial m_{t}^{l p^{2}}} \frac{\left(V^{l}-V^{c}\right)}{1+r} \leq 0 .{ }^{33}
$$

\subsubsection{The Supply of Commercial Lobbying Services}

The first-order condition (2.14) describes the optimal number of clients with respect to the costs of processing clients' proposals and the current market lobbying service fee. This is summarized by:

Lemma 1. The optimal size of the lobbying firm in $t, n_{t}^{l}$, depends on the market lobbying service fee in $t$ with $k_{t}>0$ such that

$$
k_{t}=G^{\prime}\left(n_{t}^{l}\right)
$$

A lobbyist chooses the number of clients based on the current rewards received in the market of commercial lobbying services. The decision does not depend on the relationship with a policymaker and a potential reward received in the market for political access. The lobbyist's best-response can be described by $n_{t}^{*}=n\left(k_{t}\right)$.

\subsubsection{The Lobbyist's Financial Contribution}

Part of each policymaker's political access rule is the minimum financial contribution of $\bar{f}^{l p}$. Each lobbyist knows that the policymaker can identify perfectly in $t+1$ whether or not the lobbyist made the minimum financial contribution in $t$. If the lobbyist makes a financial contribution less than the minimum, $f_{t}^{l p}<\bar{f}^{l p}$, then the policymaker terminates the relationship. A lobbyist has no incentive to make a financial contribution in excess of

\footnotetext{
${ }^{33}$ In the following the partial derivatives for $\delta\left(\bar{q}^{l p}\right)$ with respect to $m_{t}^{l p}$ are written as $\delta_{m}\left(\bar{q}^{l p}\right)$ and $\delta_{m m}\left(\bar{q}^{l p}\right)$.
} 
the minimum, $f_{t}^{l p}>\bar{f}^{l p}$, indeed if they did then the policymaker might expect, because of the lobbyist's resource constraint, that they may not have allocated sufficient resources to the verification of proposals. This would have either an adverse effect on the duration of the relationship or would not maximize a lobbyist's profit. This can be summarized as the following:

$$
f_{t}^{*}= \begin{cases}0 & \text { if } V^{l}<V^{c} \text { for a given } \bar{q}_{t}^{l p} \text { or } \\ \bar{f}_{t}^{l p} & \text { if } V^{l} \geq V^{c} \text { for a given } \bar{q}_{t}^{l p} .\end{cases}
$$

The lobbyist's stationary participation constraint, $V^{l} \geq V^{c}$, follows from (2.11) with $\Pi^{l}=V^{l}$ as well as the expected lifetime payoff for a citizen such that:

$$
\begin{aligned}
\Pi^{l}=k n^{l}-G\left(n^{l}\right)-F\left(m^{l p}\right)-f^{l p}+\frac{\delta\left(\bar{q}^{l p}\right)}{1+r} V^{c}+\frac{\left(1-\delta\left(\bar{q}^{l p}\right)\right)}{1+r} V^{l} & \geq V^{c} \\
V^{l}=\frac{(1+r)\left(k n^{l}-G\left(n^{l}\right)-F\left(m^{l p}\right)-f^{l p}\right)}{r+\delta\left(\bar{q}^{l p}\right)}+\frac{\delta\left(\bar{q}^{l p}\right)}{r+\delta\left(\bar{q}^{l p}\right)} V^{c} & \geq V^{c} \\
(1+r)\left(k n^{l}-G\left(n^{l}\right)-F\left(m^{l p}\right)-f^{l p}\right) & \geq r V^{c} .
\end{aligned}
$$

\subsubsection{The Lobbyist's Verification Effort}

The first-order condition (2.15) describes the optimal amount of verification efforts given the policymaker's announced quality threshold, $\bar{q}_{t}^{l p}$. As long as there are promised future benefits to being a lobbyist, $V^{l}-V^{c}>0$, and the lobbyist's verification effort decreases the likelihood of being dropped in the future, $\delta_{m}\left(\bar{q}_{t}^{l p}\right)<0$, the lobbyist undertakes a positive level of unobservable verification effort so as to maintain the relationship with the policymaker. ${ }^{34}$ So if a policymaker wants to induce a lobbyist to undertake effort, then the policymaker has to ensure positive future profits and monitor the lobbyist's presented portfolio. This can be summarized by:

Proposition 1. Lobbyists provide positive levels of unobservable verification efforts in $t$ whenever policymakers can promise future benefits and lobbyists' verification efforts decrease the likelihood of being dropped by a policymaker.

\footnotetext{
${ }^{34}$ This follows from $F^{\prime}(0)=0$ and that $F($.$) is increasing convex. Therefore E\left[\Pi^{l}(0)\right]>0$ and $E\left[\Pi^{l}(\infty)\right]<0$ such that $m_{t}^{*}>0$ would be a unique solution to $\frac{\partial E\left[\Pi^{l}\right]}{\partial m_{t}^{l_{p}}}=0$.
} 
Note that the solution to (2.15) and (2.17) might not be unique with multiple optimal levels of verification efforts. ${ }^{35}$ This would imply that the lobbyist's best-response, $m_{t}^{*}$, is not a continuous function. However, the important result is that a policymaker can escape a "cheap talk" lobbying game if they interact repeatedly with the same commercial lobbyist. ${ }^{36}$ Each lobbyist has an incentive ex ante to promise verification efforts in exchange for political access but has no incentive ex post to undertake those efforts in an one-shot lobbying game. So if a policymaker is able to promise future rents and can at least imperfectly monitor verification efforts, then lobbyists have an incentive to provide unobservable verification effort so as to gain future profits. ${ }^{37}$ It is therefore not optimal for a policymaker to meet with different lobbyists or to allow free entry into the political establishment, as this would diminish a lobbying contacts' profits and verification efforts. Using (2.15) and (2.17), the sufficient condition for a globally optimal level of verification effort, and a continuous best-response function, can be summarized by the following:

\section{Assumption 1. It holds that}

$$
\frac{F^{\prime \prime}\left(m_{t}^{l p}\right)}{F^{\prime}\left(m_{t}^{l p}\right)}>\frac{\delta_{m m}\left(\bar{q}^{l p}\right)}{\delta_{m}\left(\bar{q}^{l p}\right)} .
$$

The assumption ensures a unique optimal verification effort if $n_{t}^{l}>m_{t}^{l p}$. This assumption is maintained for the remaining analysis. ${ }^{38}$

The best-response function for the lobbyist's verification effort can be described by the

\footnotetext{
${ }^{35}$ See Rogerson (1985) for a general discussion of the multiplicity problem in principal-agent frameworks.

${ }^{36}$ For example, Crawford and Sobel (1982) show how a better-informed sender partitions strategically the information about the state to influence a decision maker's choice. Krishna and Morgan (2001) focus on circumstances with one lobby or two lobbies, which have similar or opposite bias, have also partitioning equilibria. Austen-Smith (1995) focuses on campaign contributions that increase the likelihood of receiving political access in a first-stage lobbying game and that have reveal some information about the interest group's preference. However, a policymaker has no means to evaluate the credibility of a lobby's speech in the second stage. Here, a commercial lobbyist is not strategic about the information itself but about the verification costs.

${ }^{37}$ This result is standard in the efficiency wage literature. In order to induce unobservable costly efforts, employers offer higher wages to employees that increase the employees' opportunity costs of shirking and dismissal.

${ }^{38}$ As noted earlier, the normal probability distribution does not fulfill Jewitt's (1988) general sufficient conditions for the first-order approach. Since an approximation to a Poisson probability distribution is desirable but not feasible, the analysis faces a trade-off between a problematic statistical approximation and additional assumptions about the lobbyist's cost structure to justify the first-order approach, which keeps the analysis tractable. It seems more reasonable to proceed with an additional assumption. The assumption follows Esfahani and Salehi-Isfahani (1989).
} 
exogenous variables of the model, as well as the variables that individual lobbyist's treat as parametric. This can be summarized by the following:

$$
m_{t}^{*}=m\left(\bar{q}_{t}^{l p}, \bar{f}_{t}^{l p}, \tilde{a}_{t}^{l p}, k_{t}\right)
$$

The steady state verification effort follows from the notion that the political access rule does not change from period to period and that $m_{t}^{l p}=m_{t+1}^{l p}$ for all $t$. Using $\Pi^{l}=V^{l}$, the lobbyist's expected lifetime payoff in the steady state can be written as

$$
V^{l}=\frac{(1+r)\left(k n^{l}-G\left(n^{l}\right)-F\left(m^{l p}\right)-f^{l p}\right)}{r+\delta\left(\bar{q}^{l p}\right)}+\frac{\delta\left(\bar{q}^{l p}\right) V^{c}}{r+\delta\left(\bar{q}^{l p}\right)}
$$

which reduces to

$$
V^{l}-V^{c}=\frac{(1+r)\left(k n^{l}-G\left(n^{l}\right)-F\left(m^{l p}\right)-f^{l p}\right)-r V^{c}}{r+\delta\left(\bar{q}^{l p}\right)} .
$$

The first-order condition (2.15) for an interior solution with $n_{t}^{l}>m^{l p}$ can be written as

$$
(1+r) F^{\prime}\left(m^{l p}\right)=-\delta_{m}\left(\bar{q}^{l p}\right) \frac{(1+r)\left(k n^{l}-G\left(n^{l}\right)-F\left(m^{l p}\right)-f^{l p}\right)-r V^{c}}{r+\delta\left(\bar{q}^{l p}\right)}
$$

this reduces to

$$
-F^{\prime}\left(m^{l p}\right) \frac{r+\delta\left(\bar{q}^{l p}\right)}{\delta_{m}\left(\bar{q}^{l p}\right)}=k n^{l}-G\left(n^{l}\right)-F\left(m^{l p}\right)-f^{l p}-\frac{r V^{c}}{1+r} .
$$

The first term on the left-hand side is the marginal cost of verification. The numerator of the second factor expresses the effective discount rate for being a lobbyist in the future; the denominator expresses the marginal change in the likelihood of not being dropped by the policymaker. On the right-hand side of (2.26) is the net benefit of being a lobbyist. Note that in steady state, $k n^{l}$ is affected by the clients' willingness to pay for lobbying services, which depends on the lobbyist's steady state political access to a policymaker. The interpretation is straightforward: The policymaker has to grant less political access to the lobbyist in order to induce verification efforts if either the effective discount rate or the 
effect of verification efforts on the likelihood of not being dropped is relatively small. Using (2.26), the steady verification effort can be written as a function of $\tilde{a}^{l p}, \bar{q}^{l p}, \bar{f}^{l p}$, and $k-$ i.e., $m^{*}=m\left(\tilde{a}^{l p}, \bar{q}^{l p}, \bar{f}^{l p}, k\right)$. The steady financial contribution is either $f^{*}=0$ or $f^{*}=\bar{f}^{l p}$, and the number of clients follows from $n^{*}=n(k)$.

\subsection{The Policymaker's Optimization Problem}

Each policymaker knows the lobbyists' best-responses to $\tilde{a}^{l p}($.$) and takes the outcomes$ of the lobbying service market, $k_{t}$ and $n_{t}^{l}$, as given. A policymaker is also not strategic about the behavior of other policymakers and takes their actions, $A_{t}^{-p}$, as given, that is we assume the policymakers play a Nash game between themselves. The policymaker maximizes his expected lifetime payoff by choosing $\tilde{a}_{t}^{l p}, \bar{q}_{t}^{l p}$, and $\bar{f}_{t}^{l p}$ and taking their effects on the lobbyists' best-responses into account.

Each policymaker has no incentive to allocate time to citizens as long as lobbyists provide sufficient resources in exchange for political access - i.e., $A_{t}^{p}=\sum_{l=1}^{l_{t}^{p}} \tilde{a}_{t}^{l p}$. However, a policymaker does not want to enact proposals that have received negative verification signals and are in expected terms undesirable. To this end the policymaker announces a minimum quality standard $\bar{q}^{l p}$.

In a steady state, the policymaker's optimization problem can be written as maximizing per period payoffs given by

$$
\begin{aligned}
\max _{\bar{q}^{l p}, \bar{f}^{l p}, \tilde{a}^{l p}, l^{p}} E\left[\Pi^{p}\right]= & \theta+\alpha \sum_{l=1}^{l^{p}} f^{l p}+\frac{1}{T} E\left[\sum_{c \in A^{-p}} e^{c}\right] \\
& +\frac{s}{T}\left(\rho\left(x^{+}\right) \sum_{l=1}^{l^{p}} m^{l p}\left[\rho\left(e^{+} \mid x^{+}\right)-\rho\left(e^{-} \mid x^{+}\right)\right]\right) \\
& +\frac{s}{T}\left(\sum_{l=1}^{l^{p}}\left(\tilde{a}^{l p}-\rho\left(x^{+}\right) m^{l p}\right)\left[\rho\left(e^{+}\right)-\rho\left(e^{+}\right)\right]\right)
\end{aligned}
$$

s.t. the policymaker's time constraint

$$
A^{p}=\sum_{l=1}^{l^{p}} \tilde{a}^{l p},
$$


the lobbyists participation constraint, which employing (2.20) may be written

$$
(1+r)\left[k n^{l}-G\left(n^{l}\right)-F\left(m^{l p}\right)-f^{l p}\right] \geq r V^{c} \text { for all } l^{p},
$$

and the lobbyists incentive compatibility constraint

$$
-F^{\prime}\left(m^{l p}\right) \frac{r+\delta\left(\bar{q}^{l p}\right)}{\delta_{m}\left(\bar{q}^{l p}\right)}=k n^{l}-G\left(n^{l}\right)-F\left(m^{l p}\right)-f^{l p}-\frac{r V^{c}}{1+r} .
$$

We see immediately that the policymakers time constraint determines $l^{p}$, leaving $\bar{q}^{l p}, \bar{f}^{l p}, \tilde{a}^{l p}$ as the remaining choice variables. From the lobbyist's participation constraint, $V^{l} \geq V^{c}$, and employing (2.20) we get

$$
(1+r)\left[k n^{l}-G\left(n^{l}\right)-F\left(m^{l p}\right)-f^{l p}\right] \geq r V^{c} \text { for all } l^{p},
$$

which holds with inequality whenever $m^{*}>0$ because of the lobbyist's first-order condition described in (2.15). The lobbyist's incentive compatibility constraint (2.26) is binding and determines verification effort whenever $n^{l}>m^{l p}$, viz

$$
-F^{\prime}\left(m^{l p}\right) \frac{r+\delta\left(\bar{q}^{l p}\right)}{\delta_{m}\left(\bar{q}^{l p}\right)}=k n^{l}-G\left(n^{l}\right)-F\left(m^{l p}\right)-f^{l p}-\frac{r V^{c}}{1+r} .
$$

When the lobbyists participation constraint is non-binding then using (2.32) and substituting for $f^{l p}$, the policymaker's problem can be reduced to

$$
\begin{aligned}
\max _{\bar{q}^{l p}, \bar{f}^{l p}, \tilde{a}^{l p}} E\left[\Pi^{p}\right]= & \theta+\alpha \sum_{l=1}^{l^{p}}\left(k n^{l}-G\left(n^{l}\right)-F\left(m^{l p}\right)-\frac{r V^{c}}{1+r}+F^{\prime}\left(m^{l p}\right) \frac{r+\delta\left(\bar{q}^{l p}\right)}{\delta_{m}\left(\bar{q}^{l p}\right)}\right) \\
& +\frac{s}{T}\left(\rho\left(x^{+}\right) \sum_{l=1}^{l^{p}} m^{l p}\left[\rho\left(e^{+} \mid x^{+}\right)-\rho\left(e^{-} \mid x^{+}\right)\right]\right) \\
& +\frac{s}{T}\left(\sum_{l=1}^{l^{p}}\left(\tilde{a}^{l p}-\rho\left(x^{+}\right) m^{l p}\right)\left[\rho\left(e^{+}\right)-\rho\left(e^{+}\right)\right]\right)
\end{aligned}
$$


The first-order condition with respect to the minimum quality threshold is then

$$
\begin{aligned}
\frac{\partial E\left[\Pi^{p}\right]}{\partial \bar{q}^{l p}}= & \alpha\left[-F^{\prime}\left(m^{l p}\right) \frac{\partial m^{*}}{\partial \bar{q}^{l p}}+F^{\prime \prime}\left(m^{l p}\right) \frac{\partial m^{*}}{\partial \bar{q}^{l p}} \frac{r+\delta\left(\bar{q}^{l p}\right)}{\delta_{m}\left(\bar{q}^{l p}\right)}\right. \\
& \left.+F^{\prime}\left(m^{l p}\right) \frac{\delta_{m}\left(\bar{q}^{l p}\right)^{2}-\delta_{m m}\left(\bar{q}^{l p}\right)\left(r+\delta\left(\bar{q}^{l p}\right)\right)}{\delta_{m}\left(\bar{q}^{l p}\right)^{2}}\right] \\
& +\frac{\rho\left(x^{+}\right) s}{T}\left[\rho\left(e^{+} \mid x^{+}\right)-\rho\left(e^{-} \mid x^{+}\right)-\rho\left(e^{+}\right)+\rho\left(e^{-}\right)\right] \frac{\partial m^{*}}{\partial \bar{q}^{l p}}
\end{aligned}
$$

and for the minimum desired financial contribution is

$$
\begin{aligned}
\frac{\partial E\left[\Pi^{p}\right]}{\partial \bar{f}^{l p}}= & \alpha\left[-F^{\prime}\left(m^{l p}\right) \frac{\partial m^{*}}{\partial \bar{f}^{l p}}+F^{\prime \prime}\left(m^{l p}\right) \frac{\partial m^{*}}{\partial \bar{f}^{l p}} \frac{r+\delta\left(\bar{q}^{l p}\right)}{\delta_{m}\left(\bar{q}^{l p}\right)}\right] \\
& +\frac{\rho\left(x^{+}\right) s}{T}\left[\rho\left(e^{+} \mid x^{+}\right)-\rho\left(e^{-} \mid x^{+}\right)-\rho\left(e^{+}\right)+\rho\left(e^{-}\right)\right] \frac{\partial m^{*}}{\partial \bar{f}^{l p}} .
\end{aligned}
$$

One way to view the solution to the policymakers problem is that in the steady state, given the equilibrium in the lobbying services market, they provide each lobbyist with just enough political access to induce them to supply the required expected verification effort and level of financial contributions. Furthermore should any lobbyist decide to shirk, or is simply unlucky with the proposals they receive from their clients, then the policymaker dismisses them and replaces them with a new lobbyist. The policymaker finds this optimal so as to prevent future shirking.

\subsubsection{The Interior Solution: Verification Effort and Financial Contribution}

As a first step, suppose the policymaker's problem has an interior solution with $\bar{q}^{l p}>0$ and $\bar{f}^{l p}>0$. It follows from $(2.35)$ equal to zero, $\frac{\partial m^{*}}{\partial f^{l p}}<0$ and $(2.26)$ that

$$
F^{\prime}\left(m^{l p}\right) \underbrace{-F^{\prime \prime}\left(m^{l p}\right) \frac{r+\delta\left(\bar{q}^{l p}\right)}{\delta_{m}\left(\bar{q}^{l p}\right)}}_{(a)}=\frac{\rho\left(x^{+}\right) s}{\alpha T}\left[\rho\left(e^{+} \mid x^{+}\right)-\rho\left(e^{-} \mid x^{+}\right)-\rho\left(e^{+}\right)+\rho\left(e^{-}\right)\right] .
$$

Note that the left-hand side of (2.36) is increasing in $m^{l p}$ and for a given $\bar{q}^{l p}$ has a unique solution. ${ }^{39}$ Further, (2.36) is similar to Groll and Ellis (2012) with observable verification

\footnotetext{
${ }^{39}$ This follows from $F^{\prime \prime}()>$.0 and $F^{\prime \prime \prime}() \geq$.0 .
} 
efforts except for the second term on the left-hand side, $(a)$, which expresses the imperfect monitoring of verification effort. This can be summarized as to the following:

Proposition 2. The desired unobservable verification effort depends on the trade-off faced by the policymaker between expected spillover shares and financial contributions. Further, the desired level of verification effort per firm is less than in the full information scenario.

The comparison to the full information scenario follows from utilizing proposition 4 of Groll and Ellis (2012). ${ }^{40}$ The policymaker's trade-off between their share of social spillovers and private benefits from financial contributions is similar in both scenarios except that the policymaker recognizes that when verification effort cannot be directly observed the marginal value of additional effort to the lobbyist is decreased. In essence because the policymaker must respect the lobbyists incentive compatibility constraint the minimum quality requirement they set is lower than the quality they would expect to receive with optimal monitoring in a full information environment.

To obtain the solution for the optimal verification effort consider $(2.34)$ with $\frac{\partial E\left[\Pi^{p}\right]}{\partial f^{l p}}=0$ and employ (2.36); the optimal quality threshold, $\bar{q}^{*}$, then follows from

$$
F^{\prime}\left(m^{l p}\right) \frac{\delta_{m}\left(\bar{q}^{l p}\right)^{2}-\delta_{m m}\left(\bar{q}^{l p}\right)\left(r+\delta\left(\bar{q}^{l p}\right)\right)}{\delta_{m}\left(\bar{q}^{l p}\right)^{2}}=0
$$

such that

$$
\delta_{m}\left(\bar{q}^{l p}\right)^{2}=\delta_{m m}\left(\bar{q}^{l p}\right)\left(r+\delta\left(\bar{q}^{l p}\right)\right)
$$

Using (2.36) and (2.38), it can be solved for the optimal verification effort of $m^{*}$ given $\bar{q}^{*}$. Given the outcomes for the commercial lobbying service market, the optimal minimum financial contribution of $\bar{f}^{*}$ follows from the lobbyist's incentive compatibility condition, described in (2.32), and the pair $\left\{\bar{q}^{*}, m^{*}\right\}$.

\subsubsection{Corner Solution: Verification Effort}

Now suppose $\alpha=0$ implying that a policymaker does not value financial contributions.

Therefore each sets $\bar{f}_{m}^{l p}=0$ to maximize lobbyists' available resources for verification efforts

\footnotetext{
${ }^{40}$ The proposition is restated in the Appendix 7.3.1.
} 
and a lobbyist who would make a financial contribution would be dropped. So a lobbyist's best-response is $f_{m}^{*}=0$. The first-order condition for the quality threshold with $\alpha=0$ is

$$
\frac{\partial E\left[\Pi^{p}\right]}{\partial \bar{q}^{l p}}=\frac{\rho\left(x^{+}\right) s}{T}\left[\rho\left(e^{+} \mid x^{+}\right)-\rho\left(e^{-} \mid x^{+}\right)-\rho\left(e^{+}\right)+\rho\left(e^{-}\right)\right] \frac{\partial m^{*}}{\partial \bar{q}^{l p}} .
$$

It follows that $\frac{\partial E\left[\Pi^{p}\right]}{\partial \bar{q}^{l p}}=0$ implies that $\frac{\partial m^{*}}{\partial \bar{q}^{l p}}=0$. This is similar to Esfahani and SalehiIsfahani (1989) with a general bell-shaped distribution. The derivation is the following: Using the lobbyist's best-response, (2.26), and differentiating with respect to $\bar{q}^{l p}$, and imposing $\frac{\partial m^{*}}{\partial \bar{q}^{l p}}=0$ implies that

$$
\frac{r+\delta^{\prime}\left(\bar{q}^{l p}\right)}{\delta_{m}^{\prime}\left(\bar{q}^{l p}\right)}=0
$$

It follows that a policymaker chooses a $\bar{q}^{l p}$ that solves (2.40). That a solution to this problem exists follows from noting that the relationship between the minimum quality level, $\bar{q}^{l p}$, and the optimal verification response of the lobbyist is not monotonic. At low levels of $\bar{q}^{l p}$ an increase in this minimum quality requirement increases verification, whereas for $\bar{q}^{l p}$ sufficiently high an increase in this minimum quality requirement decreases verification. It follows that (2.40) displays at least one maximum. The global maximum for $(2.40)$ depends on the distribution function $\delta($.$) , which is characterized in section 2.4.1$ as an approximated normal distribution. Given the shape of the normal density function, the maximum is global and unique. Using the unique value of $\bar{q}_{m}^{*}$ that solves (2.39) and the lobbyist's stationary first-order condition from (2.26), the corresponding $m^{*}$ solves

$$
F\left(m^{l}\right)+\left.F^{\prime}\left(m^{l}\right) \frac{r+\delta\left(\bar{q}^{l p}\right)}{\delta_{m}\left(\bar{q}^{l p}\right)}\right|_{\bar{q}^{l p}=\bar{q}_{m}^{*}}=k n^{l}-G\left(n^{l}\right)-\frac{r V^{c}}{1+r}
$$

and is unique because of the convexity of $F($.$) and F^{\prime}($.$) .$

\subsubsection{Corner Solution: Financial Contribution}

Finally, suppose policymakers do not value verification efforts sufficiently and desire only financial contributions. A policymaker avoids providing any incentives for costly verification effort as it reduces a lobbyist's resources and hence chooses a quality threshold of $\bar{q}_{f}^{*}=0$. Since a policymaker can monitor perfectly a lobbyist's current financial contribu- 
tion in $t+1$, the policymaker takes only the participation constraint into account and tries to extract all available rents. It follows that the participation constraint is binding. The optimal financial contribution minimum follows from (2.31) with

$$
\frac{V^{l}-V^{c}}{1+r}=f_{t}^{l p}
$$

Using the stationary expected payoff described in (2.24) with $V^{l}-V^{c}$, it follows that

$$
V^{l}-V^{c}=\frac{(1+r)\left(k n^{l}-G\left(n^{l}\right)-f^{l p}\right)}{r}-V^{c}
$$

so (2.42) and (2.43) jointly imply

$$
k n^{l}-G\left(n^{l}\right)-\frac{r V^{c}}{1+r}=(1+r) \bar{f}_{f}^{*}
$$

with $f_{f}^{*}=\bar{f}_{f}^{*}$.

\section{Equilibrium}

The equilibrium is characterized by a steady state in the markets for labor, commercial lobbying services, and political access. The labor market is in equilibrium if the inflow of citizens into the lobbying industry is equal to the outflow of lobbyists who have lost political access to policymakers and return to being citizens. The market for commercial lobbying services is in equilibrium if the demand equals the supply of intermediation services. Finally, the political access market is in equilibrium if there is a Nash equilibrium between policymakers in choosing political access rules, given that citizens and lobbyists are best responding to these announced rules. In the following, the equilibrium with an interior solution to the policymaker's problem is derived. The equilibrium for each corner solution can be found in the Appendicies 7.1 and 7.2, respectively. In what follows we characterize the symmetric steady state equilibrium. 


\subsection{Lobbying Labor Market}

Given that $\delta_{t} L_{t}$ lobbyists lose political access at the beginning of period $t$, that is revert to being citizens, and that both they and the those members of the population that entered the period as citizens may potentially enter the market for political access, it follows that the probability of entering the market for political access and becoming a lobbyist for a citizen, $h_{t}$, is

$$
h_{t}=\frac{\delta_{t} L_{t}}{C_{t}+\delta_{t} L_{t}}
$$

We may employ this transition probability to write the value asset equation for a citizen written as

$$
V^{c}=h_{t} \Pi^{l}+\left(1-h_{t}\right)\left(\Pi_{t}^{c}+\frac{V^{c}}{1+r}\right)=h_{t} \Pi^{l}+\left(1-h_{t}\right) \Pi_{t}^{c}+\frac{\left(1-h_{t}\right) V^{c}}{1+r}
$$

with

$$
V^{c}=\frac{(1+r)\left(h_{t} \Pi^{l}+\left(1-h_{t}\right) \Pi_{t}^{c}\right)}{r+h_{t}} .
$$

The value asset equation for a lobbyist follows from the lobbyist's expected lifetime payoff in the steady state as described in (2.23). Given the opportunity for access, the citizen's entry decision depends on whether $V^{l} \geq V^{c}$.

\subsection{Market for Lobbying Services}

The citizens' demand for commercial lobbying with political capture by lobbyists in $t$ follows from (2.3). Since lobbying firms are identical, the market demand for commercial lobbying services can be written as

$$
k_{t}=k\left(n_{t}^{l}\right)=\frac{\tilde{a}_{t}^{l p}}{n_{t}^{l}} \pi^{c} \text { for every } l \text { and } t
$$

Each lobbying firms takes the market fee, $k_{t}$, as given and determines its optimal size. Using lemma 1, the supply of commercial lobbying services solves

$$
k_{t}=k\left(n_{t}^{l}\right)=G^{\prime}\left(n_{t}^{l}\right) \text { for every } l \text { and } t
$$


Using the market demand (3.4) and the market supply (3.5), the equilibrium condition for the lobbying service market can be written as

$$
\frac{\bar{P} A^{p}}{n_{t}^{l}} \pi^{c}=G^{\prime}\left(n_{t}^{l}\right) \text { for every } l \text { and } t
$$

The market clearing lobbying service fee thus depends on the number of clients, lobbyists' political access, the private benefit of an enacted policy proposal, and the cost of processing proposals.

\subsection{Market for Political Access}

As shown in the policymaker's problem, policymakers want to employ all political resources and have no incentive to allocate political access to citizens - i.e., $A_{t}=\bar{P} A^{p}$ and $\tilde{a}_{t}^{c}=0$. In the symmetric case the political access for each lobbyist can be written as

$$
\tilde{a}_{t}^{l p}=\frac{\bar{P} A^{p}}{L_{t}} \text { for every } t
$$

The number of presented unverified proposals and the number of proposals disappearing in the lobbying firm follow from

$$
n_{t}^{l}=m_{t}^{l p}+u_{t}^{l p}+r_{t}^{l} \text { for every } l \text { and } t
$$

and the lobbyist's portfolio of presented proposals from

$$
\tilde{a}_{t}^{l p}=\rho\left(x^{+}\right) m_{t}^{l p}+u_{t}^{l p} \text { for every } l \text { and } t .
$$

The announced quality threshold, $\vec{q}_{t}^{l p}$, follows from (2.38); the number of verified proposals for $n_{t}^{l}>m_{t}^{l p}$ follows from (2.36). Finally, the required minimum financial contribution, $\bar{f}_{t}^{l p}$, follows from $\bar{q}^{*}, m^{*}$, and the lobbyist's incentive compatibility constraint (2.32). The lobbyist's best-response to $\bar{f}^{*}$ is $f^{*} \geq \bar{f}^{*}$ depending on $V^{l} \geq V^{c}$. 


\subsection{Solution}

The full symmetric steady state equilibrium is characterized by the previously described equilibrium conditions and the population constraint

$$
T=C_{t}+L_{t}+\bar{P}
$$

where $\bar{P}$ follows from the constitution. The number of lobbyists can be written as

$$
L_{t}=\frac{T-\bar{P}}{1+n_{t}^{l}}
$$

because of $C_{t}=L_{t} n_{t}^{l}$ and (3.10).

In the steady state all endogenous variables, $X$, of the system do not vary over time i.e., $X_{t}=X_{t+1}$. First, using (3.6), (3.7), and (3.11), the equilibrium number of clients per firm follows from

$$
\left.\frac{n^{*}}{1+n^{*}} \frac{\partial G\left(n^{l}\right)}{\partial n^{l}}\right|_{n^{l}=n^{*}}=\frac{\bar{P} A^{p} \pi^{c}}{T-\bar{P}} .
$$

The equilibrium number of clients is positive and unique. ${ }^{41}$ The equilibrium lobbying service fee follows immediately such that

$$
k^{*}=\left.\frac{\partial G\left(n^{l}\right)}{\partial n^{l}}\right|_{n^{l}=n^{*}} .
$$

Using (3.11) and (3.12), the equilibrium number of lobbyists and citizens is

$$
L^{*}=\frac{T-\bar{P}}{1+n^{*}} \text { and } C^{*}=L^{*} n^{*}
$$

Each lobbying firm receives political access of

$$
\tilde{a}^{*}=\frac{\bar{P} A^{p}}{L^{*}}
$$

in exchange for lobbying efforts. The lobbying efforts are best-responses to the announced political access rule of $\left\{\tilde{a}^{*}, \bar{q}^{*}, \bar{f}^{*}\right\}$, where the equilibrium minimum quality threshold fol-

\footnotetext{
${ }^{41}$ See Groll and Ellis (2012).
} 
lows from $(2.38)$ such that

$$
\left.\delta_{m}\left(\bar{q}^{l p}\right)^{2}\right|_{\bar{q}^{l p}=\bar{q}^{*}}=\left.\delta_{m m}\left(\bar{q}^{l p}\right)\left(r+\delta\left(\bar{q}^{l p}\right)\right)\right|_{\bar{q}^{l p}=\bar{q}^{*}} .
$$

The corresponding equilibrium best-response for the verification effort follows from (2.36) such that

$$
\begin{aligned}
& \left.\left(F^{\prime}\left(m^{l p}\right)-\left.F^{\prime \prime}\left(m^{l p}\right) \frac{r+\delta\left(\bar{q}^{l p}\right)}{\delta_{m}\left(\bar{q}^{l p}\right)}\right|_{\bar{q}^{l p}=\bar{q}^{*}}\right)\right|_{m^{l p}=m^{*}} \\
= & \frac{\rho\left(x^{+}\right) s}{\alpha T}\left[\rho\left(e^{+} \mid x^{+}\right)-\rho\left(e^{-} \mid x^{+}\right)-\rho\left(e^{+}\right)+\rho\left(e^{-}\right)\right] .
\end{aligned}
$$

Using (3.9) and the equilibrium values from (3.15) and (3.17), the equilibrium of unverified presented proposals per firm follows from (3.9) such that

$$
u^{*}=\tilde{a}^{*}-\rho\left(x^{+}\right) m^{*}
$$

The equilibrium number of proposals that disappear in each lobbying firm follows from (3.8) with (3.12), (3.17), and (3.18) such that

$$
r^{*}=n^{*}-m^{*}-u^{*}
$$

The equilibrium inflow of citizens into the lobbying industry follows from (3.1), (3.14), and (3.16) such that

$$
h^{*}=\frac{\delta^{*}}{n^{*}+\delta^{*}} .
$$

The equilibrium value for the citizen's expected lifetime payoff follows from the notion that there is private rent-dissipation for citizens in equilibrium - i.e., $\Pi_{t}^{c}=0$ - and that a positive expected lifetime payoff is entirely determined by potential entry and positive rents for lobbyists. ${ }^{42}$ It follows from (3.3) that

$$
V^{c}=\frac{(1+r) h^{*} \Pi^{l}}{r+h^{*}}
$$

\footnotetext{
${ }^{42}$ This follows from the citizen's willingness to pay and the equilibrium service fee described in (3.6).
} 
The steady state values for $\Pi^{l}, V^{l}, V^{c}, \bar{f}^{l p}$, and $f^{l p}$ can be solved with $\Pi^{l}=V^{l},(2.19)$, (2.23), (2.26), and (3.21). Using (2.23) and (3.21), the following can be obtained

$$
V^{l}=\frac{(1+r)\left(k n^{l}-G\left(n^{l}\right)-F\left(m^{l p}\right)-f^{l p}\right)(r+h)}{r\left(r+h+\delta\left(\bar{q}^{l p}\right)(1-h)\right)} .
$$

Using (2.26) and (3.21), it follows that

$$
f^{l p}=k n^{l}-G\left(n^{l}\right)-F\left(m^{l p}\right)+F^{\prime}\left(m^{l p}\right) \frac{r+\delta\left(\bar{q}^{l p}\right)}{\delta_{m}\left(\bar{q}^{l p}\right)}-\frac{r h}{r+h} V^{l} .
$$

The equilibrium minimum financial contribution can be derived with (3.22) and (3.23) such that

$$
\bar{f}^{*}=k^{*} n^{*}-G\left(n^{l}\right)-\left.F^{\prime}\left(m^{l p}\right) \frac{r+\delta\left(\bar{q}^{l p}\right)}{\delta_{m}\left(\bar{q}^{l p}\right)} \frac{r+h^{*}+\delta\left(\bar{q}^{l p}\right) r\left(1-h^{*}\right)}{r+\delta\left(\bar{q}^{l p}\right)\left(1-h^{*}\right)-r h^{*}}\right|_{n^{l}=n^{*}, m^{l p}=m^{*}, \bar{q}^{l p}=\bar{q}^{*}}
$$

with the lobbyist's equilibrium best-response of $f^{*}=\bar{f}^{*}$. The expected lifetime payoff for a lobbyist in the steady state is

$$
V^{l *}=\left.\left(k^{*} n^{*}-G\left(n^{l}\right)-F^{\prime}\left(m^{l p}\right) \frac{r+\delta\left(\bar{q}^{l p}\right)}{\delta_{m}\left(\bar{q}^{l p}\right)}-f^{*}\right) \frac{r+h^{*}}{r h^{*}}\right|_{n^{l}=n^{*}, m^{l p}=m^{*}, \bar{q}^{l p}=\bar{q}^{*}} .
$$

Finally, the expected lifetime payoff for a citizen in the steady state is

$$
V^{c *}=\frac{(1+r) h^{*}}{r+h^{*}} V^{l *}
$$

\section{Social Value of Cronyism}

We now consider the normative implications of our equilibrium results. We discuss the distribution of private benefits for lobbyists and citizens and analyze the social desirability of commercial lobbying activities in the presence of asymmetric information. First, we compare the previously characterized payoffs for citizens and lobbyists with the results of commercial lobbying with perfectly monitored verification efforts. Surprisingly, citizens and lobbyists realize private benefits that are not present with perfect information and a 
perfectly contestable lobbying market. Second, we analyze the general welfare implications of commercial lobbying with repeated personal interactions and barriers to entry. We find that welfare effects are ambiguous, but are able to characterize when lobbying is and is not welfare improving.

If there is a steady state with both a positive level of verification effort and financial contributions, then it follows from proposition 1 and (3.26) that $V^{l *}>V^{c *}>0$. Compared to Groll (2012) who finds that there is perfect private rent dissipation but incomplete social rent dissipation under commercial lobbying with observable lobbying efforts, we do not find perfect private rent dissipation. ${ }^{43}$ We can state that both lobbyists and citizens realize expected private benefits and are both better off with respect to private benefits than in the scenario with perfect observability of lobbying efforts. Here, lobbyists realize information rents, which are promised by policymakers' access rules, and citizens realize private rents from potential entry into the commercial lobbying industry.

Proposition 3. The repeated personal interactions between lobbyists and policymakers in the presence of asymmetric information as well as the resulting barriers to political entry create private benefits for both citizens and lobbyists and do not result in a private rent dissipation as observed in the perfect information equilibrium.

This result is contrary to the public's skeptical view regarding close personal relationships between lobbyists and policymakers. If there were free entry into the political access market (ignoring the lack of credibility of entrants to provide costly lobbying efforts), then the competition between citizens and lobbyists would dissipate their expected private rents and policymakers gain additional rents (as shown in Groll, 2012). Here, the promised information rents for lobbyists create expected private benefits. However, citizens also realize private benefits in comparison to the lobbying game with perfectly monitored lobbying efforts. Their expected private rents arise because of potential (limited) entry into the commercial lobbying industry. We argue then that the skeptical view of lobbying held by the public is correct in the sense that lobbyists do indeed realize information rents created

\footnotetext{
${ }^{43}$ The private rent dissipation focuses on citizens' and lobbyists' private payoffs excluding spillover shares. The incomplete social rent dissipation arises because citizens and lobbyists do not internalize their spillover shares in their lobbying decisions. The proposition we are referring to is restated in Appendix 7.3.2.
} 
by barriers to entry, however what this view fails to realize is that in the absence of entry barriers not only would policymakers capture all information rents from lobbyists but that they would also capture those rents that would have "filtered down" to citizens.

The quality of political decisions and their implications for social welfare depend on the policymakers' preferences and choice of political access rules. The welfare implications can be summarized as in the following:

Proposition 4. The social welfare effects of commercial lobbying with asymmetric information are ambiguous. Asymmetric information may actually improve welfare outcomes in comparison to perfect information.

If commercial lobbying is socially desirable and verification efforts are unobservable, then it would be desirable to have both political capture by lobbyists and repeated personal interactions between lobbyists and policymakers with barriers to political entry (proposition 1). However, if verification efforts are unobservable, then verification efforts at the firm-level are lower (proposition 2) but the equilibrium number of lobbyists is unaffected. This implies that the social welfare implications can be obtained from proposition 2 and Groll and Ellis (2012). ${ }^{44}$ If there is an oververification at the firm-level, then a policymaker's imperfect monitoring may improve social outcomes; if there is an underverification at the firm-level, then imperfect monitoring may worsen social welfare. To summarize, the general welfare implications of repeated personal interactions depend on whether these interactions solve a policymaker's information problem (verification efforts) or a policymaker's contracting problem (financial contributions).

\section{Conclusion}

This study provides an explanation for observed repeated personal interactions between lobbyists and policymakers. In the presence of asymmetric information about lobbyists' information improvements or the absence of binding contracts, policymakers have an incentive to initiate repeated personal interactions with lobbyists to solve their information and

\footnotetext{
${ }^{44}$ Their proposition is for the reader restated in Appendix 7.3.3.
} 
contracting problem. Lobbyists undertake current verification efforts and make promised financial contributions if repeated personal relationships promise them positive future profits. These rents arise when policymakers create barriers to entry and restrict the political establishment. If policymakers would not be able to promise future rents and to at least imperfectly monitor verification efforts, then lobbyists have no incentive to provide costly effort and policymakers would be trapped in a repeated "cheap talk" lobbying game. If commercial lobbying is socially desirable, then repeated personal interactions between lobbyists and policymakers improve social welfare outcomes. It has been shown that the welfare implications depend on the policymakers' preferences and the monitoring of verification efforts. Further, the verification efforts are less than in the full information scenario. However, imperfect information may improve welfare outcomes if policymakers cause an oververification at the firm-level otherwise.

The current analysis has focused on policymakers and abstracted from elected representatives. Nevertheless, the analysis can provide some insights for unobservable lobbying efforts and term limits for elected officials. Using the current analysis, a term limit would imply that a lobbyist has no incentive to provide any efforts to a policymaker who is in his last period of office. If politicians use repeated interactions to coordinate campaign contributions, then term limits would improve welfare. However, if repeated interactions solve a policymaker's information problem, then term limits would be socially undesirable. 


\section{References}

[1] Austen-Smith, D. (1994). Strategic Transmission of Costly Information, Econometrica 62 (4), 955-963.

[2] Austen-Smith, D. (1995). Campaign Contributions and Access, American Political Science Review 89 (3), 263-280.

[3] Becker, A. (2010). Multitudes of Lobbyists Weigh in on Dodd-Frank Act, The Washington Post November 22nd 2010.

[4] Bennedsen, M., Feldmann, S. E. (2002). Lobbying Legislatures, Journal of Political Economy 110 (4), 919-948.

[5] Bennedsen, M., Feldmann, S. E. (2006). Informational Lobbying and Political Contributions, Journal of Public Economics 90, 631-656.

[6] Bernheim, B., D., Whinston, M. D. (1986). Menu Auctions, Resource Allocation, and Economic Influence, Quarterly Journal of Economics 101 (1), 1-31.

[7] Bertrand, M., Bombardini, M. and Trebbi, F. (2011). 'Is It Whom You Know or What You Know? An Empirical Assessment of the Lobbying Process', mimeo. http://faculty.arts.ubc.ca/ftrebbi/research/mbt.pdf

[8] Besley, T., Coate, S. (2001). Lobbying and Welfare in a Representative Democracy, Review of Economic Studies 68, 67-82.

[9] Black, D. A., Garen, J. E. (1991). Efficiency Wages and Equilibrium Wages, Economic Inquiry 29, 525-540.

[10] Blanes i Vidal, J., Draca, M., Fons-Rosen, C. (2011). Revolving Door Lobbyists, American Economic Review forthcoming.

[11] Buchanan, J. M. (1980). Rent-Seeking and Profit-Seeking, in: Buchanan, J. M., Tollison, R. D., Tullock, G. (eds), Toward a Theory of the Rent-Seeking Theory, Texas A\&M University Press, College Station, 3-15.

[12] The Center for Ethics in Government. 50 State Chart: Contingency Fees, National Congress of State Legislators, updated June 2010. http://www.ncsl.org/Default.aspx?TabId=15351 (accessed May 2nd, 2011, pdf on hand).

[13] Congleton, R. D., Hillman, A. L., Konrad, K. A. (2008). 40 Years of Research on Rent Seeking, vol. 1-2, Springer: Berlin, Germany. 
[14] Crawford, V. P., Sobel, J. (1982). Strategic Information Transmission, Econometrica 50, 1431-1451.

[15] Dahm, M., Porteiro, N. (2008). Informational Lobbying under the Shadow of Political Pressure, Social Choice and Welfare 30 (4), 531-559.

[16] Dewatriport, M., Tirole, J. (1999). Advocates, Journal of Political Economy 107 (1), $1-39$.

[17] Diamond, D. W. (1991). Reputation and Monitoring, Journal of Political Economy 99 (4), 689-721.

[18] Eggers, A. (2010). Partisan Revolving Door, mimeo. http://andy.egge.rs/papers/partisan_revolving_door.pdf

[19] Eisler, K. (2007). Hired Guns: The City's 50 Top Lobbyists, Washingtonian June 1st 2007.

[20] Esfahani, H. S., Salehi-Isfahani, D. (1989). Effort Observability and Worker Productivity: Towards an Explanation of Economic Dualism, Economic Journal 99, 818-836.

[21] Fahrmeir, L., Künstler, R., Pigeot, I., Tutz, G. (1997). Statistik, Springer: Berlin.

[22] Gathmann, F., Weisensee, N. (2007). Lobbyisten-Liste enthüllt Einfluss in Ministerien, Spiegel Online July 26th 2007.

[23] Gilligan, T., Krehbiel, K. (1989). Asymmetric Information and Legislative Rules with a Heterogeneous Committee, American Political Science Review 33 (2), 459-490.

[24] Groll, T. (2012). Commercial Lobbying, Optimal Institutions and Political Reforms, mimeo.

[25] Groll, T., Ellis, C. J. (2012). A Simple Model of the Commercial Lobbying Industry, mimeo. http://www. columbia.edu/ tg2451/research/Simple\%20Lobbying\%20Model\% 20-\%20August\%202012_groll_ellis_online.pdf

[26] Grossman, G., Helpman, E. (1994). Protection for Sale, American Economic Review $84(4), 833-850$.

[27] Grossman, G., Helpman, E. (2001). Special Interest Politics, MIT Press: Cambridge, MA.

[28] Holmstrom, B. (1981). Contractual Models of the Labor Market, American Economic Review 71 (2), 308-313. 
[29] Jewitt, I. (1988). Justifying the First-Order Approach to Principal-Agent Problems, Econometrica 56 (5), 1177-1190.

[30] Krishna, V., Morgan, J. (2001). A Model of Expertise, Quarterly Journal of Economics $116(2), 747-775$.

[31] Kroszner, R. S., Stratmann, T. (1998). Interest-Group Competition and the Organization of Congress: Theory and Evidence from Financial Services' Political Action Committees, American Economic Review 88 (5), 1163-1187.

[32] Krueger, A. O. (1974). The Political Economy of the Rent-Seeking Society, American Economic Review 64 (3), 291-303.

[33] Lohmann, S. (1995). Information Access and Contributions: A Signaling Model of Lobbying, Public Choice 85, 267-284.

[34] Olson, M. (1965). The Logic of Collective Action: Public Goods and the Theory of Groups, Harvard University Press: Cambridge, MA.

[35] Oppong, M., Steinmann, T. (2012). Lobbyisten nisten sich in Regierung ein, Financial Times Deutschland April 5th 2012.

[36] Pear, R. (2009). In House, Many Spoke With One Voice: Lobbyists', The New York Times November 15th 2009.

[37] Potters, J., Winden, F. v. (1992). Lobbying and Asymmetric Information, Public Choice 74, 269-292.

[38] Rogerson, W. P. (1985). The First-Order Approach to Principal-Agent Problems, Econometrica 53 (6), 1357-1367.

[39] Schmidt, S., Grimaldi, J. V. (2005). The Fast Rise and Steep Fall of Jack Abramoff, The Washington Post December 29th 2005.

[40] Schmidt, S., Grimaldi, J. V. (2006). Abramoff Pleads Guilty to 3 Counts, The Washington Post January 4th 2006.

[41] The Senate Office for Public Records. Lobbying Disclosure Act Guidance, United States Senate, reviewed December 15th 2010.

[42] Selten, R. (1978). The Chain-Store Paradox, Theory and Decision 9, 127-159.

[43] Shapiro, C., Stiglitz, J. E. (1984). Equilibrium Unemployment as a Worker Discipline Device, American Economic Review 74 (3), 433-444.

[44] Sparks, R. (1986). A Model of Involuntary Unemployment and Wage Rigidity: Worker Incentives and the Threat of Dismissal, Journal of Labor Economics 4 (4), 560-581. 
[45] Tullock, G. (1967). The Welfare Costs of Tariffs, Monopolies, and Theft, Western Economic Journal 5, 224-232.

[46] Tullock, G. (1980). Efficient Rent-Seeking, in: Buchanan, J. M., Tollison, R. D., Tullock, G. (eds), Toward a Theory of the Rent-Seeking Theory, Texas A\&M University Press, College Station, 97-112. 


\section{Appendix}

\subsection{Equilibrium for Corner Solution: Verification Effort}

The equilibrium conditions for the lobbying labor market and the market for commercial lobbying services are not affected by a corner solution for the policymaker's problem with respect to verification efforts. It still holds that

$$
\left.\frac{n^{*}}{1+n^{*}} \frac{\partial G\left(n^{l}\right)}{\partial n^{l}}\right|_{n^{l}=n^{*}}=\frac{\bar{P} A^{p} \pi^{c}}{T-\bar{P}}
$$

and the equilibrium values of $k^{*}, L^{*}, C^{*}$, and $\tilde{a}^{*}$ are identical. However, each policymaker sets $\bar{f}_{m}^{l p}=0$ and maximizes the resources available for verification efforts. Lobbyists make no financial contributions, $f_{m}^{*}=\bar{f}_{m}^{*}=0$, because it would signal a waste of resources. Equilibrium conditions of (3.7), (3.8), and (3.9) still hold. Each policymaker sets $\bar{q}^{l p}$ such that $\frac{\partial m^{*}}{\partial \bar{q}^{l p}}=0$. It has been shown that there is a unique $\bar{q}_{m}^{*}$ and therefore a unique steady state dismissal rate of $\delta_{m}^{*}$. The steady state entry into the lobbying industry follows from $h_{m}^{*}=\frac{\delta_{m}^{*}}{n^{*}+\delta_{m}^{*}}$.

It still holds that there is a private rent dissipation for citizens as characterized in (7.1) - i.e., $\Pi_{t}^{c}=0$ - and that $\Pi^{l}=V^{l}$ in steady state. The value asset equation for a citizen follows from (3.3). The steady state first-order condition with respect to verification effort is characterized in (2.41). Finally, the value asset equation for a lobbyist without financial contributions can be written as

$$
V^{l}=\frac{(1+r)\left(k n-G(n)-F\left(m^{l p}\right)\right)}{r+\delta\left(\bar{q}^{l p}\right)}+\frac{\delta\left(\bar{q}^{l p}\right)}{r+\delta\left(\bar{q}^{l p}\right)} V^{c} .
$$

Using (3.3), (2.41), and (7.2), the steady state verification effort is

$F\left(m^{l p}\right)+F^{\prime}\left(m^{l p}\right) \frac{r+\delta\left(\bar{q}^{l p}\right)}{\delta\left(\bar{q}^{l p}\right)} \frac{r+h_{m}^{*}+\delta\left(\bar{q}^{l p}\right)\left(r-r h_{m}^{*}\right)}{\left(r+\delta\left(\bar{q}^{l p}\right)\right)\left(1-h_{m}^{*}\right)}=k^{*} n^{*}-\left.G\left(n^{l}\right)\right|_{m^{l p}=m_{m}^{*}, \bar{q}^{l p}=\bar{q}_{m}^{*}, n^{l}=n^{*}} ;$

the expected lifetime payoff for a lobbyist is

$$
V^{l *}=\left.\frac{(1+r)\left(r+h_{m}^{*}\right)\left(k^{*} n^{*}-G\left(n^{l}\right)-F\left(m^{l p}\right)\right)}{r\left(r+h_{m}^{*}+\delta\left(\bar{q}^{l p}\right)\left(1-h_{m}^{*}\right)\right)}\right|_{n^{l}=n^{*}, \bar{q}^{l p}=\bar{q}_{m}^{*}} ;
$$

and the expected lifetime payoff for a citizen is

$$
V^{c *}=\frac{(1+r) h_{m}^{*}}{r+h_{m}^{*}} V^{l *}>0
$$

Finally, $u_{m}^{*}=\tilde{a}^{*}-\rho\left(x^{+}\right) m_{m}^{*}$ and $r_{m}^{*}=n^{*}-m_{m}^{*}-u_{m}^{*}$. 


\subsection{Equilibrium for Corner Solution: Financial Contribution}

The equilibrium conditions for the market for commercial lobbying services are not affected by a corner solution for the policymaker's problem with respect to financial contributions. It still holds that

$$
\left.\frac{n^{*}}{1+n^{*}} \frac{\partial G\left(n^{l}\right)}{\partial n^{l}}\right|_{n^{l}=n^{*}}=\frac{\bar{P} A^{p} \pi^{c}}{T-\bar{P}}
$$

and the equilibrium values for $k^{*}, L^{*}, C^{*}$, and $\tilde{a}^{*}$ are identical. However, each policymaker sets $\bar{q}_{f}^{l p}=0$ and maximizes rents through financial contributions. Lobbyists undertake no verification efforts, $m_{f}^{*}=0$, and make the required financial contributions since policymakers can identify perfectly whether or not a lobbyist made the required financial contribution - i.e., $f_{f}^{*}=\bar{f}_{f}^{*}$. The lobbyist's equilibrium portfolios are characterized by $u_{f}^{*}=\tilde{a}^{*}$ and $r_{f}^{*}=n^{*}-u_{f}^{*}$.

In steady state, there is a no exit out of and entry into the lobbying industry and political access market. It follows that $\delta_{f}^{*}=0$ and $h_{f}^{*}=0$. The lifetime expected payoff for a citizen follows from (3.3) with $\Pi_{t}^{c}=0$, because of the expected private rent dissipation for citizens, such that

$$
V^{c *}=\frac{(1+r) \Pi_{t}^{c}}{r}=0
$$

Using (2.44), the steady minimum financial contribution is

$$
\bar{f}_{f}^{*}=\left.\frac{k^{*} n^{*}-G\left(n^{l}\right)}{1+r}\right|_{n^{l}=n^{*}}
$$

with $f_{f}^{*}=\bar{f}_{f}^{*}$. Finally, the expected lifetime payoff for a lobbyist follows from $(2.44)$ and is

$$
V_{f}^{l *}=(1+r) \bar{f}_{f}^{*}
$$

with $V_{f}^{l *}>V_{f}^{c *}=0$. Policymakers can extract larger rents from lobbyists because of the better monitoring of financial contributions but they still have to share rents with lobbyists to induce promised and legally nonenforceable financial contributions.

\subsection{Unpublished Results}

Here, we summarize briefly some unpublished results from Groll and Ellis (2012) as well as Groll (2012).

\subsubsection{Policymaker's Lobbying Effort Requests}

Proposition (Groll and Ellis, 2012). The solution to the policymaker's problem with observable verification efforts and financial contributions may take one of four possible forms dependent on parameter values: 
1. If the solution is at a corner with respect to verified proposals, then all approved policy proposals received positive verification signals. All remaining rents are extracted by policymakers via financial contributions.

2. If the solution is at a corner with respect to verified and unverified proposals, then then the solution to the policymaker's problem involves lobbyists verifying $m^{c o}$ proposals, which exhaust a lobbyist's financial resources, and presenting those proposals which received a positive verification signal together with sufficient unverified proposals to exhaust access. No rents are extracted via financial contributions because of a sufficiently small $\alpha$. The amount of verification at the firm-level is determined by

$$
F\left(m^{c o}+\sum_{h \neq p} m^{l h}\right)=n^{l} k-\sum_{h \neq p} f^{l h}-G\left(n^{l}\right)-E\left[\Pi^{c} \mid \text { private ben. }\right] .
$$

3. If the solution is interior with respect to verification and financial contributions, then

the policymaker's problem involves lobbyists verifying $m^{\#}$ proposals, and presenting those proposals which received a positive verification signal together with sufficient unverified proposals to exhaust access. All remaining rents are extracted by policymakers via financial contributions. The amount of verification at the firm-level is determined by

$$
\frac{\partial F\left(m^{l}\right)}{\partial m^{l p}}=\rho\left(x^{+}\right) \frac{s}{\alpha T}\left[\rho\left(e^{+} \mid x^{+}\right)-\rho\left(e^{-} \mid x^{+}\right)-\rho\left(e^{+}\right)+\rho\left(e^{-}\right)\right] .
$$

4. If the solution is at a corner with respect to financial contributions and the following holds

$$
\alpha>\rho\left(x^{+}\right) \frac{s}{T}\left(\rho\left(e^{+} \mid x^{+}\right)-\rho\left(e^{-} \mid x^{+}\right)-\rho\left(e^{+}\right)+\rho\left(e^{-}\right)\right),
$$

then all approved proposals are unverified. All rents are extracted by policymakers via financial contributions.

\subsubsection{Private Rent Dissipation}

Proposition (Groll, 2012). All expected private rents for citizens and lobbyists are dissipated. However, not all social rents are dissipated.

The competition for political access by citizens and lobbyists as well as the resource requests by self-interested policymakers, who can monitor perfectly the lobbying activities by lobbyists, extract all expected private rents from citizens and lobbyists. The result is similar to contest functions in the rent-seeking literature and in tradition of Tullock (1980). These rent-seeking contests induce individuals competing for a prize to expend resources such that with an increasing number of competitors these political investments equal the 
prize. Here, the presence of policy spillovers and competition for private rents may lead to incomplete social rent dissipation.

\subsubsection{Social Welfare of Full Information Equilibrium}

Proposition (Groll and Ellis, 2012). Comparing the verification effort levels for the full information social welfare optimum and the requests by policymakers under the full information market outcome, we have

$$
\left.\left.\frac{\partial F\left(m^{l}\right)}{\partial m^{l}}\right|_{m^{l}=m^{*}} \gtreqless \frac{1}{\alpha T-1} \frac{\partial G\left(n^{l}\right)}{\partial n^{l}}\right|_{n^{l}=m^{*}} \Rightarrow m^{\#} \lesseqgtr m^{*} .
$$

Proposition 5 is intuitive once we recognize that there are several distortions in operation. First, each policymaker receives only a share of aggregate spillovers and therefore does not fully internalize all benefits from improved political decisions. Second, a policymaker does not internalize the costs of verifying proposals, and an socially undesirable oververification at the firm-level is more likely. Finally, a policymaker faces a trade-off between privately beneficial financial contributions and socially desirable spillover improvements, which may cause either an underverification (high $\alpha$ ) or underverification (low $\alpha$ ). 